San Jose State University

SJSU ScholarWorks

Master's Theses

Master's Theses and Graduate Research

1992

\title{
An analysis of three communication-based pedagogies and their critiques of traditional pedagogy in higher edcuation
}

Mia Angela Hoglund

San Jose State University

Follow this and additional works at: https://scholarworks.sjsu.edu/etd_theses

\section{Recommended Citation}

Hoglund, Mia Angela, "An analysis of three communication-based pedagogies and their critiques of traditional pedagogy in higher edcuation" (1992). Master's Theses. 395.

DOI: https://doi.org/10.31979/etd.8t3a-mty4

https://scholarworks.sjsu.edu/etd_theses/395

This Thesis is brought to you for free and open access by the Master's Theses and Graduate Research at SJSU ScholarWorks. It has been accepted for inclusion in Master's Theses by an authorized administrator of SJSU ScholarWorks. For more information, please contact scholarworks@sjsu.edu. 


\section{INFORMATION TO USERS}

This manuscript has been reproduced from the microfilm master. UMI films the text directly from the original or copy submitted. Thus, some thesis and dissertation copies are in typewriter face, while others may be from any type of computer printer.

The quality of this reproduction is dependent upon the quality of the copy submitted. Broken or indistinct print, colored or poor quality illustrations and photographs, print bleedthrough, substandard margins, and improper alignment can adversely affect reproduction.

In the unlikely event that the author did not send UMI a complete manuscript and there are missing pages, these will be noted. Also, if unauthorized copyright material had to be removed, a note will indicate the deletion.

Oversize materials (e.g., maps, drawings, charts) are reproduced by sectioning the original, beginning at the upper left-hand corner and continuing from left to right in equal sections with small overlaps. Each original is also photographed in one exposure and is included in reduced form at the back of the book.

Photographs included in the original manuscript have been reproduced xerographically in this copy. Higher quality $6 " \mathrm{x} 9$ " black and white photographic prints are available for any photographs or illustrations appearing in this copy for an additional charge. Contact UMI directly to order.

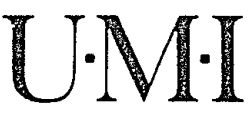

Universily Microfilms International

A Bell \& Howell Information Company

300 North Zeeb Road. Ann Arbor. MI 48106-1346 USA

313:761.4700 800:521.0600 
- 
Order Number 1950089

An analysis of three communication-based pedagogies and their critiques of traditional pedagogy in higher education

Hoglund, Mia Angela, M.A.

San Jose State University, 1992

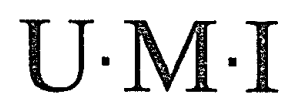

300 N. Zeeb Rd.

Ann Arbor, MI 48106 



\title{
AN ANALYSIS OF THREE COMMUNICATION-BASED PEDAGOGIES AND THEIR CRITIQUES OF TRADITIONAL PEDAGOGY IN HIGHER EDUCATION
}

\author{
A Thesis \\ Presented to \\ The Faculty of the Communication Studies Department \\ San Jose State University
}

In Partial Fulfillment

of the Requirements for the Degree

Master of Arts

By

Mia Angela Hoglund

August 1992 
APPROVED FOR THE DEPARTMENT OF COMMUNICATION STUDIES
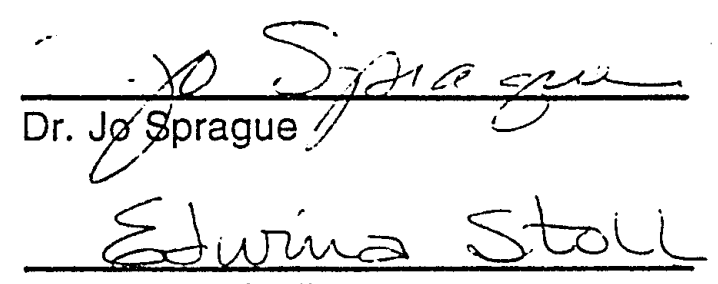

Dr. Edwina Stolly

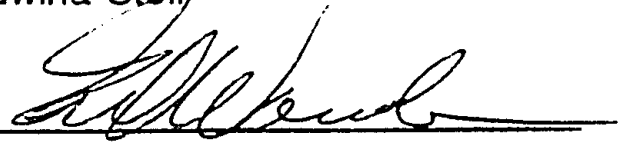

Dr. Philip Wander

APPROVED FOR THE UNIVERSITY

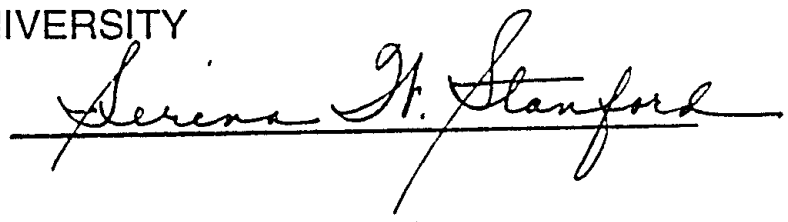




\begin{abstract}
AN ANALYSIS OF THREE COMMUNICATION-BASED PEDAGOGIES AND THEIR CRITIQUES OF TRADITIONAL PEDAGOGY IN HIGHER EDUCATION

by Mia Angela Hoglund
\end{abstract}

This thesis is a critical interpretive analysis of three socially-based pedagogies-cooperative/collaborative, liberatory, and humanist. This paper summarizes their critiques of the traditional lecture method of instruction at the college level and compares them based on a thematic analysis. Eight prominent themes from education were selected for the thematic analysis: Teacher-student relationship, Learning context, Goals, Teacher and student responsibility/roles, Knowledge, Power, Student relationship with peers, and Evaluation. These themes were identified in representative texts by the following authors: Ira Shor and Paulo Freire (liberatory); David and Roger Johnson, Kenneth Bruffee, Jane Mouton and Robert Blake (cooperative/collaborative); Mary Field Belenky, Blythe McVicker Clinchy, Nancy Rule Goldberger, Jill Mattuck Tarule; Parker Palmer, and Nell Noddings (humanist).

The final chapter of this thesis compares the alternatives in a synthesis of thematic analyses. Implications for Instructional Communication as well as suggestions for future research are made. Research indicates that the practice of teaching in college classrooms does not reflect what is known about communication. These socially-based pedagogies question the basic assumptions of education, knowledge, and the traditional lecture method, and emerge as legitimate alternatives that should be considered by teachers and teacher-educators. 


\section{ACKNOWLEDGEMENTS}

Space will not allow me to thank the many teachers whose influence contributed to this project. While writing this paper, I was reminded of every teacher in my educational experience. Much of my thinking about this project lead me to a question I will probably always pursue, "What makes a good teacher?" Earning my Masters Degree at San Jose State afforded me the opportunity to work with many good teachers who have all helped me form an answer to that question. I would like to specifically thank several people particularly influential to me and the completion of this project.

I would like to thank Dr. Jo Sprague, my advisor and friend, for her time, patience, and care for this project. Dr. Sprague has been an outstanding thesis advisor who has sacrificed countless hours of time for me. I am truly grateful to her for her dedication as a learning mentor. I will continue to aspire to her level of dedication to her students.

Dr. Edwina Stoll contributed to this project by encouraging me to talk about teaching. I would like to thank Dr. Stoll for being a supportive friend and role-model for me as an outstanding teacher and for her comments and advise about this project.

I am grateful to Dr. Philip Wander who created the ideal learning space to help me find my voice in graduate school. Without Dr. Wander's encouraging words I would not have had the confidence in my writing ability to tackle such a large project.

I would also like to thank Dr. David Elliott for his influence as my first-year intern advisor and for being a wonderful department chair. His probing questions encouraged me to think deeply about teaching. 
I. INTRODUCTION............................................................................ 1

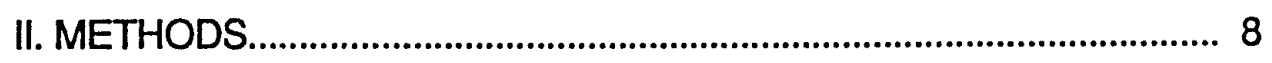

Selection of Representative Texts................................................... 9

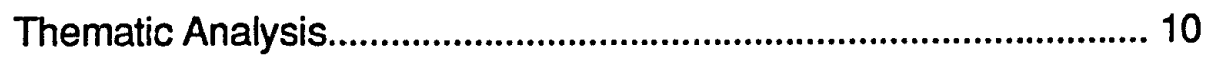

III. LIBERATORY PEDAGOGY.......................................................... 17

Ovenview of Liberatory Pedagogy....................................................... 17

Liberatory Critique of Traditional Education..................................... 21

Thematic Analysis: Critical Teaching and Everyday Life............. 23

Thematic Analysis: A Pedagogy for Liberation ............................. 32

Communication and Liberatory Pedagogy...................................... 41

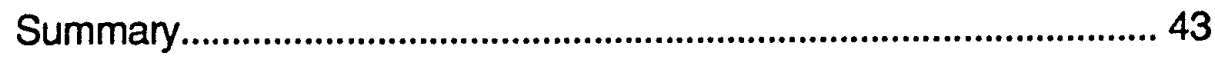

IV. COOPERATIVE/COLLABORATIVE PEDAGOGY........................... 44

Overview of Cooperative/Collaborative Pedagogy........................ 44

Cooperative/Collaborative Critique of Traditional Education...... 49

Thematic Analysis: Ceoperation in the Classroom........................ 52

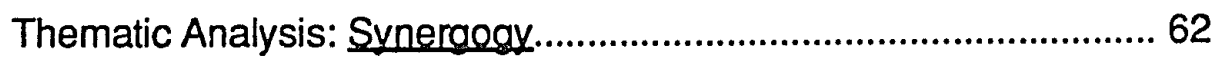

Thematic Analysis: "Collaborative Learning and the

'Conversation of Mankind'.................................................................. 70

Communication and Cooperative/Collaborative Pedagogy....... 75

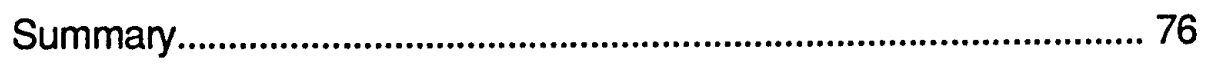

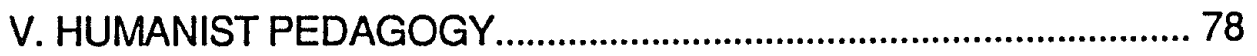

Overview of Humanist Pedagogy..................................................... 78

Humanist Critique of Traditional Education.................................... 81 
Thematic Analysis: Io Know As We Are Known.......................... 84

Thematic Analysis: "An Ethic of Caring and Its

Implications for Instructional Arrangements"................................. 92

Thematic Analysis: Women's Ways of Knowing............................ 97

Communication and Humanist Pedagogy.................................... 104

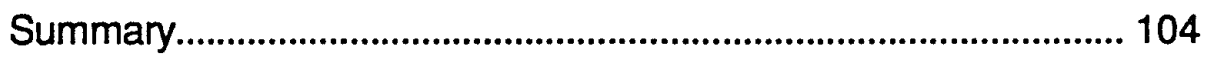

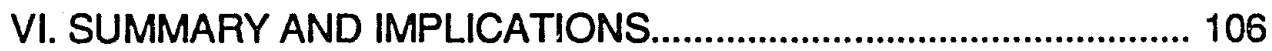

Synthesis of Thematic Analyses..................................................... 107

Dialectic Tensions of Alternative Pedagogies............................. 116

Implications for Instructional Communication................................ 124

Suggestions for Future Research............................................... 124 


\section{CHAPTER ONE}

\section{INTRODUCTION}

To teach is to create a space in which the community of truth is practiced. Truth is an eternal conversation about things that matter, conducted with passion and discipline. Good teaching, whatever its form, will help more and more people learn to speak and listen in the community of truth, to understand that truth is not in the conclusions so much as in the process of conversation itself, that if you want to be "in truth" you must be in the conversation. (1990, p.12)

This quotation from Parker Palmer suggests a fresh approach to teaching in college classrooms. Where many teachers of college students endorse an environment where students passively take notes and quietly copy a lecture, some college instructors and theorists have realized alternatives. Three current and significant educational movements are discussed in this paper, grouped under the headings of liberatory, cooperative/collaborative, and humanist pedagogy. The similarities and differences of these pedagogies are explained through an analysis of representative texts. In spite of their varied perspectives, educators from all three of these groups would agree with Parker Palmer's quotation and his assumption that learning and knowledge occur through a social process.

Good communication is the key factor in the learning process. Staton (1988) argues that the relationship between communication and education is obvious when definitions of the two are compared. Since acquiring knowledge, or developing and changing attitudes and behaviors depends on successful attempts to construct shared meanings and understandings, it follows that instruction is a communicative process and it is through speaking and listening that learning occurs (Staton, 1988). Researchers agree that pedagogy is a social activity relying heavily on the interactive processes of speaking and 
listening (Daly \& Korinek, 1980; Galvin \& Cooper, 1981; Friedrich, 1989; Soltis, 1984). It is clear from the writings of these experts that an attempt at learning without effective communication is inherently futile, or at best, a frustrating experience for both teachers and students. Although researchers have studied interaction in classrooms since 1912 (Daly \& Korinek, 1980) many scholars who study education at the college level have expressed the need for more research that focuses on the central role of communication in the instruction process (Galvin \& Cooper, 1981; Sprague, 1992; Staton-Spicer \& Wulff, 1984). Sadly, the call for more research by communication scholars has not provided the instructional communication field with evidence that the practice of teaching in college classrooms reflects what is known about communication.

Research on the subject of classroom instruction at the college level reveals some assumptions that have been made about communication. The process-product paradigm, the model that predominated the field since 1963, treats the classroom as an environment for information exchange. As Shulman (1986) says, "process-product researchers view classrooms as reducible to discrete events and behaviors that can be noted, counted and aggregated for purposes of generalizations across settings and individuals" (p. 20). This linear view of communication neglects the potential for dynamic interaction. The process-product model is a naive approach to the explanation of students' understanding that has allowed researchers to name communication variables as predictors of learning. Another dimension to this critique is the emphasis upon the interpersonal dimension of the teacher-student relationship rather than the intellectual learning that takes place in the classroom (Sprague, 1992). 
By being overly concerned with the interpersonal relations between teachers and students, researchers have trivialized the role of the instructor while ignoring the more important issue, that of the actual learning process.

In college classrooms, lecturing is the predominant method of instruction (Daly \& Korinak, 1980). Most college professors have very little background in pedagogy, so professors teach others the way they were taught and carry on the "tradition." Anyone who visits a typical college classroom today can testify that not much has changed since 1909 when one observer wrote:

In the American classroom, 'clearly the master is the textbook.' The teacher does not really teach but acts rather as chairman of a meeting, the object of which is to ascertain whether [or not the students] have studied for themselves in a textbook." (Burstall, cited in Tharp \& Gallimore, 1988, p. 13)

In 1980, Smith claimed, "At all grade levels the predominant method of teaching was recitation (discussion) with the teacher in control, supplementing the lesson with new information (lecturing). The key to the information and basis for reading assignments was the textbook" (cited in Tharp \& Gallimore, 1988). Common teaching practices have been condemned as "'nonteaching' by successive waves of reform," yet they survive virtually unchanged (Tharp \& Gallimore, 1988, p. 4).

Traditional education has received a great deal of criticism from educational practitioners and scholars in recent years. Traditional pedagogy is a broad term that suggests several ideas. First, it suggests the view that knowledge is a quantitative measurable property available to those who have mastered the text. Knowledge is perceived as static and understood as something objective that the teacher owns and the students must possess. If knowledge in a traditional classroom is assumed to be a property, it can be 
transfered from one person to another through transmission and memorization. In a recent article that claims to summarize what is known about communication in higher education, Bruschke and Gartner claim that teachers are "charged with a specific and vital duty; to transmit knowledge to students" (1991, p. 197). A second assumption of traditional pedagogy builds directly on this view of knowledge. The dominant mode of instruction in college classrooms, and the method that traditional pedagogy endorses is known as the lecture method. Traditional pedagogy does not reflect what is known about communication since the communication inherent in the lecture method is virtually one-way. The lecture method, which focuses on efficiency and control, is very teachercentered, and neglects the potential benefits a dynamic teacher-student and student-student relationship can produce. Finally, traditional pedagogy implies a teacher dominated environment where the instructor sets the goals and possesses virtually all of the power. If one were to represent the communication that dominates in this classroom with a diagram, it might look like this:

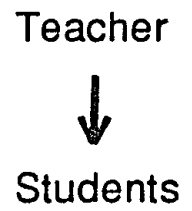

The communication in this model moves downward from teacher to student. The hierarchy implicit in this model promotes distance between teachers and students.

Despite the critiques, there are some advantages to the lecture method and logical reasons why the status quo is favored over viable alternatives that have challenged the traditional method over the years. Some merits of lecturing are that it is useful when information needs to be adapted to different 
groups, and it is often effective when the goal is for students to learn or memorize facts. When using the lecture method, information can be given quickly and efficiently. Although this method puts great pressure on the presenter, if the instructor is a skilled speaker, he or she can stimulate students to want to learn more. Lectures, when done thoughtfully, can be critical and can motivate students to think. But unfortunately, with little or no training in communication, many college instructors lack necessary public speaking skills to create and maintain interest in their lectures.

Another reason that traditional pedagogy has survived is because teachers at the college level have very little or no background in pedagogy. As previously mentioned, they teach others the way they were taught. Tradition is "familiar and already 'worked out,' even if it doesn't work out in class" (Shor \& Freire, 1987, p. 7). As Shor says, "You're on safer ground if you join the club and just lecture from the official knowledge" (Shor \& Freire, 1987, p. 44). In addition, the lecture method, for the most part, remains unchallenged by educators. The culture of higher education works against innovation. Those instructors who do experiment with alternatives methods are the exception, so there are few models from which students can learn. Also, those instructors who deviate from the norm risk being known as a 'rebel or radical or 'flake,' and can be subjected to petty harassment to firing" (Shor \& Freire, 1987, p. 7). Palmer (1983) claims that many teachers rely on the familiar method simply because it is easy. Alternative pedagogies are sometimes thought to be antiintellectual by those who rely on the standard method. A political critique also informs the explanation of the persistence of the lecture method. Supporters of this criticism see schools as delivery systems that endorse official ideas (Apple, 
1989; Giroux, 1988). Change would undermine the ability of the school system to serve as a vehicle for maintaining the political status quo. Another reason is that different pedagogies are not possible in lecture halls that hold 200 to 400 students at one time. Mass education prohibits the use of alternatives such as collaborative learning, where it is necessary that teachers be accessible to all of the small groups during one class period. This is never a problem when class sizes are fewer than thirty students. Palmer states (1983) "The conventional pedagogy persists because it conveys a view of reality that simplifies our lives" (p. 39). This method pretends to give people mastery since it offers the illusion that everything can be organized, counted, and owned. Finally, the lecture method gives the teacher the power, and therefore security which is yet another reason there exist too few pedagogical options.

This paper compares this dominant method with some hopeful alternatives. Those who advocate more socially-based pedagogies call attention to the role of communication in education and how influential it can be to learning. This study raises the question: What are some prominent critiques of traditional education that have implications for instructional communication scholarship? More specifically, this study will further explore three prominent critiques in order to answer the following: How do the alternative paradigms represented in this paper differ from traditional pedagogy? How do the alternatives differ from one another? What role does communication play in these alternatives? What assumptions are being made about communication by these paradigms? What goals of higher education do these pedagogies address? What themes from education are relevant bases for contrast? How do the alternatives discussed in this paper address these themes? What model 
of communication can be derived from examining these themes? The following chapter in this thesis will explain the methodology of the study. Chapters three, four, and five serve as the introductions to and thematic analyses of three pedagogical alternatives. Finally, chapter six will provide a synthesis of the educational alternatives chosen and draw conclusions based on an analysis of the three educational perspectives. 


\section{CHAPTER TWO}

\section{METHODS}

The goal of this critical interpretive research is to discover relevant critiques of traditional pedagogy, to synthesize their critiques, and to analyze the alternatives they advocate according to educational themes that are found in virtually all theories of education. This study will explore some alternative models of education that challenge the dominant tradition and explain how the role of communication differs within them. These approaches seem to cluster around three categories that I have named liberatory pedagogy, cooperative/collaborative pedagogy, and humanist pedagogy. This research began by a broad survey of literature dealing with critiques of traditional pedagogy. Although there are many critiques of traditional education (cf. O'Neill, 1969; Ozmon, 1970), three schools of thought were chosen for this project. These particular clusters of educational alternatives were selected based on the following criteria: all criticize traditional education, all of them address education at the college level, all of them advocate a specific alternative to the status quo, all of them advocate a socially based alternative, and all have had a significant impact on theory and practice in the field of education.

At the heart of this study is a critical thematic analysis of texts that represent the liberatory, cooperative/collaborative and humanist categories. Each school of thought is introduced with an overview of its major assumptions and a critique of traditional education. Representative texts of these three alternatives are analyzed to interpret the basic assumptions that underlie their teaching method and the implicit or explicit communication models inherent in 
each theory. After each school of thought is introduced with an overview of its major arguments and a discussion of its critique of traditional pedagogy, a thematic analysis is conducted for each representative text. The final chapter of this project synthesizes the arguments made by these pedagogies. The analysis compares and contrasts their critiques of the status quo as well as the alternatives that each advocate. The communication models that emerge from the thematic analysis will be compared. In sum, this study is designed to synthesize for the reader the three schools of thought and their critiques of traditional education and provide an analysis from a communication perspective.

\section{Selection of Representative Texts}

These three broad categories of educational iiterature are represented by selected texts that were chosen based on their ability to bridge theory and practice. In other words, in contrast to other more abstract treatises, these texts are rich with excerpts of actual classroom interaction. These eight widely cited selected texts were also chosen based on a preliminary review of the three areas, because they seemed representative of the literature and because they have clearly made an impact on the field of education. The representative texts are: Critical Teaching and Everyday Life (Ira Shor), A Pedagogy for Liberation (Paulo Freire and Ira Shor) [liberatory]; Cooperation in the Classroom (David Johnson and Roger Johnson), Synergegy (Jane Mouton and Robert Blake), "Collaborative Learning and the 'Conversation of Mankind'" (Kenneth Bruffee) [cooperative/collaborative]; and Io Knew as We are Known (Parker Palmer), "An Ethic of Caring and its Implications for Instructional Arrangements" (Nell 
Noddings), Women's Ways of Knowing (Belenky, Clinchy, Goldberger, and Tarule) [humanist].

\section{Thematic Analysis}

There are certain themes addressed by virtually every theory of education. According to Van Manen, "theme" refers to an element that occurs frequently in a text, an "experience of focus," "a simplification," and "a form of capturing the phenomenon one tries to understand" (1990, p. 87). Since themes are intransitive, thematic analysis refers to the process of recovering the themes embodied in the evolving meanings of a text (Van Manen, 1990). Identifying the themes in separate texts and comparing their similarities and differences is also a useful method to gain understanding. The themes used in this study were taken from those that appear in discussions of educational philosophy (see Booth \& Nyquist, 1977; Soltis, 1981; Sprague, 1990b; Strain, 1971). The alternative pedagogies analyzed in this paper will be compared based on the following thematic categories: Teacher-student relationship, Learning context, Goals, Teacher and student responsibility/roles, Knowledge, Power, Student relationship with peers, and Evaluation. Many times these themes overlap and are difficult to isolate. To further define these thematic categories and to illustrate the thematic analysis process, these themes are explained and used to analyze and understand the method of traditional pedagogy introduced in the previous chapter. This process also helps to establish a basis for the critique of traditional education that will follow. 


\section{Ieacher-student relationship}

The teacher-student relationship refers to the interpersonal dimension of teacher/student interaction. Related to affective learning, this thematic dimension often attracts the interest of instructors concerned with their student ratings of the instructor. The teacher-student relationship in college classrooms often differs depending upon the discipline. Most of the time, the teacherstudent relationship is a formal and impersonal one. Since all that is required in a traditional classroom is the transmission of information, the nature of most courses lend themselves to very little interaction between teachers and students. Some subjects are inclined to more involvement among teachers and students. The atmosphere in English and Speech Communication courses, for instance, often benefits from more familiar teacher/student relationships. These classes, however, are the exception. Most college instructors, even those with "small" class sizes, typically do not learn students' names or develop an individual relationships with their students.

\section{Learning context}

Communication always takes place in a context. Trenholm (1986) defines context as "the unique background against which an event or process takes shape" (p. 16). She also argues that there are at minimum two dimensions to context in every communication encounter. One is the physical, in this case, the structure of the classroom, the number of students present, the way desks are arranged, the way the rest of the classroom is set up, the frequency of communication as well as the duration of interaction. In traditional college classrooms, the instructor typically stands in front of the students, at the 
chalkboard or behind a lectern while students face the teacher in neatly organized rows of desks.

The physical context often influences the second aspect of context , or that which is influenced by the function of a social interaction (Trenholm, 1986, p. 17). Different rules accompany different communication contexts. Talking to a colleague alone in a classroom calls for one set of rules while teaching a class of thirty students in that room calls for another. While much of the physical context remains the same, the different functions change the rules for interaction. Since the function in traditional classrooms is transmission of information, the rules for students are familiar and simple. While silence and note-taking is encouraged, asking questions, arguing a point, interrupting the instructor are not. The atmosphere in a typical classroom is often anti-social and non-active. Because this atmosphere predominates with little variety, monotony also characterizes the typical traditional learning context.

\section{Goals}

This thematic dimension refers to the classroom outcomes and who controls those outcomes. As mentioned previously, the goal in the traditional classroom is usually to have students memorize a body of knowledge which occurs through the transmission of knowledge from the experts to the ignorant. The goals are always set by the teacher and are rarely negotiable. Generally, classroom goals span several levels. Immediate goals refer to the specific lesson plan for a particular period of time such as "Students will learn to write a unified and coherent five paragraph essay," while long term goals refer to the ideal end of the course, such as "Students will be required to pass a 
standardized examination," or goals that go beyond the course such as "Students will learn to be good citizens."

Teacher and student respensibility'roles

This dimension refers to the expectations that are held of teachers and students in the classroom. Students in the traditional college classroom feel their responsibility is to do their homework, memorize the given knowledge, and repeat it for examinations. Students believe they should maintain a passive role in the classroom by not talking, but listening and taking notes. Students feel little responsibility to their instructor given the impersonal relationship that exists between them, and virtually no responsibility to their peers.

Instructors who utilize expository teaching view their role to be the possessors and mediums of knowledge. They feel a responsibility to control and manage pupils, a responsibility that is usually met by establishing an atmosphere in which students play a passive role in the classroom and are encouraged to comply with the instructor's requests. In the traditional classroom, the instructor's responsibility is to deliver the information to the students. Some instructors will make an effort to present the course material in an interesting way, through examples, stories, visual aids, movies, and other resources. Few instructors, however, go beyond immediate expectations to create interesting ways to present the course content. That is, most rely on a lecture-style presentation to transmit information rather than designing more active methods of assisting student learning.

Knowledge

An important theme in every educational theory, one's conception of knowledge has powerful implications for the way that one views teaching and 
learning. All teachers presuppose a theory of knowledge. One's interpretation of knowledge raises several questions: How does one come to know? What constitutes knowledge? How does one judge between competing accounts of matters? Is knowledge apolitical and interest free? An epistemology, or theory of knowledge, raises numerous issues, among them, course content, teaching styles, grading procedures, and power relations. As stated, instructors who model the lecture method of instruction endorse a view that knowledge is an objective property possessed by the instructor. This view of knowledge assumes that the students know nothing. Students know by copying, memorizing, and repeating and what students know is essentially independent from themselves. The need to analyze, question, debate, and discuss is unnecessary because knowledge is external to human meaning. To "know" is to be able to efficiently repeat the given body of knowledge that reflects the instructor's reality. There is an implied sense of finality to the knowledge in a traditional classroom.

\section{Power}

Power can be defined in many ways. Traditionally, the research in communication education indicates that power is viewed as one-sided and something that the teacher must use in order to get students to behave. Lukes (1974) calls this type of power a view limited to the intent of A to get $B$ to do something that B would not do otherwise. In classroom communication research, power is often treated as the possession of the instructor; rarely is student power discussed. Compliance gaining research emphasizes exerting one's influence over another to get them to do something they otherwise would not (McCroskey \& Richmond, 1983). In an article mentioned previously, 
Bruschke and Gartner explain how power is conceptualized with respect to classroom management. The authors claim, "Although authoritarian discipline is no longer the norm there still remains a need for classroom management skills, largely because college students may be more sophisticated in their attempts to resist compliance" (1991, p. 199). This view is consistent with traditional classrooms. Without a voice in the discussion, it is difficult for students to have power in their classroom. Students often do, however, have the opportunity to evaluate the instructor's effectiveness. Student power is limited, then, to resistance behavior and evaluations of their instructor's teaching. For the purpose of this paper, power refers to the system of relational differentiation in who determines the outcome of the class lesson. It should be stated, however, that this view of power is considered too limited by the liberatory authors. Scholars such as Giroux and Freire would encourage an analysis of the power structure outside of the classroom.

\section{Student relationship with peers}

This thematic dimension, which is self-explanatory, is fairly consistent in traditional classrooms. Since most of the communication in a typical classroom is one to one between the instructor and the students, it seems only coincidence that students happen to be sitting with a community of peers. For the most part, students go an entire semester without knowing even the names of more than two of their classmates in most of their college classes. In traditional classrooms, students are often encouraged to compete with one another for approval of the experts. Students rarely spend time out of class together except perhaps to study for an examination. The relationship among peers is usually 
one of competition when students feel they are rivals of their classmates in pursuit of the top grade, or that their success must come at a peer's failure. Evaluation

Evaluation refers to the way in which the success of instruction is determined. Traditionally in college classrooms, students are tested individually by midterm and final examinations. In almost every case, it is the product that is being evaluated. The process is rarely examined except by a global measure at the end of the term. In any event, it is the instructor or outside groups that measure the effectiveness of the teaching. Depending on the course, papers and presentations may be required, but these are the exception in the majority of college courses. In some general education courses, students are required to complete a standardized exam that is issued throughout the department. Some colleges and universities endorse the curve grading method. This type of evaluation promotes competition among students and discourages cooperation among classmates. In this scenario, one student's success must come at a peer's failure. In general, most evaluation methods used in traditional classrooms, encourage competition rather than cooperation. 


\section{CHAPTER THREE \\ LIBERATORY PEDAGOGY \\ Qverview of Liberatory Pedagogy}

Liberatory pedagogy originated in the 1960 s. Developed by Paulo Freire, this theory was born of the economic poverty and political inexperience of Brazilian culture. It was in northeast Brazil that Freire began an educational mission in response to the massively illiterate, economically poor, and politically oppressed citizenry of his homeland. In the midst of political controversy, a government agency called SUDENE (superintendency for the development of the northeast) was established in Recife. The organization began its work with a concentration on developing the land for food and an educational program that emphasized university training. Paulo Freire was appointed coordinator of the educational effort which soon assumed the effort to include primary and adult education. He began the Angicos Literacy Experiment, and an educational revolution commenced. Freire envisioned a national educational system that would provide the scientific and technical training necessary for national survival and would address a population which, at the time, was ninety percent illiterate. Freire worked as a professor of History and Philosophy of Education at the University of Recife where his methodology became popular with Catholics and others involved with literacy campaigns in Northeast Brazil. In fact, his liberatory approach was thought to be such a threat to the old order that Paulo Freire was jailed in 1964 and exiled to Chile. There he worked with the Chilean Institute for Agrarian Reform in adult education, and later, Freire became a consultant for the School of Education at Harvard University and 
special consultant to the Office of Education of the World Council of Churches in Geneva.

Published in 1970, Pedagegy of the Oppressed, is Paulo Freire's first book to appear in print in the United States. In this book, Freire severely challenges the most predominant method of instruction that until that time had virtually survived unchallenged, so initially, his theory attracted the attention of radical educators in this country. In Pedagogy of the Oppressed, Freire introduces his liberatory pedagogy, including the prominent themes of conscientization, praxis, and dialogue, and launches a harsh critique of traditional pedagogy. It should be recognized that Marxism has played a significant role in the ongoing critique of capitalism and its institutions. Freire's critique is no exception; many of the ideas in Pedagegr of the Oppressed are familiar Marxist motifs. Not surprisingly, numerous ideas from Liberatory pedagogy find their roots in Marxism. Marxists insist that schools serve a political function, that is, the production and reproduction of labor power which insures the stability of the greater system. Marxists believe that schools legitimize the existing system of privilege, power and resources. This notion is developed more fully in Freire's book, The Politics of Education, 1985.

In order to fully understand liberatory education, one must be familiar with the ideas that undergird the theory of this alternative pedagogy. Not all of the key notions of this pedagogy appear in the thematic analyses that will follow. It is difficult to discuss these key notions as mutually exclusive, given their interdependence, but the following is an attempt to isolate them in order to better understand the liberatory approach to education. Important elements that will be introduced here are conscientization, praxis, and dialogue. 
Conscientization, or critical thinking, is the goal of liberatory education. Conscientization has to do with political literacy. It has been called both a product and process of liberatory learning (Shor, 1987, p. 48). Freire calls it "the process by which [people], not as recipients, but as knowing subjects achieve a deepening awareness both of the sociocultural reality that shapes their lives and of their capacity to transform reality" (Freire, 1985, p. 93). This term is used to describe an on-going process of developing a critical awareness of social, political, and economic reality and taking action to change oppressive conditions. Another name for critical teaching is what Freire and Shor call "reexperiencing the ordinary." This happens when students and teachers examine familiar situations in an unfamiliar way and Shor claims it can result in transcendent changes.

The term praxis which Aristotle spoke of in the Bhetoric is a common theme of Marxism. Bottomore (1983) claims that praxis is the "central concept to Marxism" (p. 348), and Bottomore further explains that praxis "refers in general to action, activity; and in Marx's sense to the free universal, creative and selfcreative activity through which man creates and changes his historical, human world, and himself; an activity specific to man, through which he is differentiated from all other beings" (p. 348). Similarly, liberatory theorists use the word to refer to the processes of reflection and action upon the world in order to transform it. This is what Freire means by liberating others, an on-going process of humans engaged in creating and re-creating culture and history. Praxis cannot be achieved at a purely intellectual level, nor can it be done through action alone. Pure intellectualism results in mere verbalism while action alone results in activism that lacks deptir (Freire, 1970). It is the human 
capacity to engage in praxis that distinguishes human beings from animals. Freire says, "Only men are praxis - the praxis which, as the reflection and action which truly transforms reality, is the source of knowledge and creation" (1970, pp. 90-91). For Freire, true knowledge evolves from the interaction of reflection and action.

If conscientization through praxis is the product of liberatory education, then dialogue is the process by which students and teachers arrive. Dialogue is the method through which liberatory educators aim to transform their students. The idea of dialogue assumes a horizontal relationship between two persons. Freire says, "Dialogue is the encounter between men, mediated by the world, in order to name the world...If it is in speaking their word that men, by naming the world, transform it, dialogue imposes itself as the way by which men achieve significance as men" (1970, pp. 76-77). In a later publication, Freire says, "Dialogue is the sealing together of the teacher and the students in the joint act of knowing and re-knowing the object of study" (Shor \& Freire, 1987, p. 14). Freire and Shor posit, "Through dialogue, reflecting together on what we know and don't know, we can then act critically to transform reality" (Shor \& Freire, 1987, p. 13). The belief that knowledge is a constant process is based on the assumption that people are "historical beings engaged in a permanent act of discovery" (Freire, 1987, p. 119). This belief lies in sharp contrast to the one introduced in the first chapter of this paper. In the traditional model of classroom communication, knowledge is viewed to be in possession of the teacher until the unknowing students copy it. The horizontal model contrasts with with the vertical model of "anti-dialogue," typical of the communication in a lecture situation. The anti-dialogue model is oppressive and exists in a matrix 
described as "loveless, arrogant, hopeless, mistrustful, acritical" (Shor, 1987, p. 95). In this scenario the relation of empathy is broken and alienation is provoked; the result is the production of static knowledge. A key feature of the liberatory model is the shared power among communicators. This calls for a change in the status quo as far as both teachers and students are concerned. Shor claims that the liberatory process of dialogue converts students from "manipulated objects into active, critical subjects" (1987, p. 97). And Freire claims that "dialogue seals the act of knowing" (Shor \& Freire, 1987, pp. 3-4).

\section{Liberatory Critique of Traditional Education}

The most prominent critique of traditional education methods by liberatory educators is best expressed by Paulo Freire's analogy of the banking concept of education. Freire utilizes the banking concept to challenge the oneway form of communication inherent in the lecture or narrative teaching method. The banking metaphor suggests that information constructed from the teacher's experience is deposited into the empty receptacles of the students' minds. This hierarchical teacher-student relationship leads to inequality, alienation, and the practice of domination in the classroom. The teacher determines what is to be known and how it should be understood and the students become recipients rather than participants in their education. Education takes place through communiques from the teachers to the students, from "those who consider themselves knowledgeable to those whom they consider to know nothing" (Freire, 1970, p. 58). When the teacher is the one who knows, thinks, and makes choices, then he or she is considered a "subject." In contrast, students are "objects" when they are assumed to be unknowing and passive recipients of knowledge. The notion of students as objects suggests that they are merely 
empty vessels waiting to be filled with the educator's knowledge where information is transferred rather than created by the learners. This teachercentered method contrasts with Freire's pedagogical approach that is more accurately described as student-centered. Freire uses the term "Subject" to refer to students who are actively and creatively involved in shaping their reality. Subjects act while objects are acted upon.

In one representative text chosen to represent liberatory pedagogy, Shor criticizes traditional education for lacking rigor which he suggests is a communication that challenges individuals to take part. Shor says, "Perhaps this is why so much formal education in classrooms fails to motivate students. The students are not included in the search, in the activity of rigor. They are told the answers to memorize." And he adds, "Knowledge is handed to them like a corpse of information-a dead 'body of knowledge'-not a living connection to their reality" (Shore \& Freire, 1987, p. 4). Shor believes that by leaving students out of the exciting process of discovering knowledge, traditional schooling relies on false motivation. He says, "Teachers and administrators and counselors are constantly lecturing them [students] on how important schooling is or what it will give them some time in the distant future. All this promoting of school only reveals its failure to motivate with the materials being studied" (Shor \& Freire, 1987, p. 5).

In general, liberatory educators believe that teachers need to account for the historical, political, ideological environment and its influence on education and our daily lives. Liberatory educators endorse the notion that education is politics, and teacher is politician working for and against something. Further, the interaction of teacher and student takes place in a political environment. 
Through their critique, liberatory educators attempt to make educators aware of the values inherent in the status quo of education. Giroux claims that "radical educators illuminate the ways in which the State, through its selective grants, certification policies, and legal powers, influence school practice in the interest of particular dominant ideologies" (1988, p. xxxi). Giroux and other critical educators have encouraged instructors to develop a "language of critique" as well as a "language of possibility" (Apple, 1989, p. 177).

Thematic Analysis: Critical Teaching and Everyday Life

In his book Critical Teaching and Evenyday Life, Ira Shor presents a practical and theoretical guide for teachers interested in adapting Freire's liberatory methods to American classrooms. Shor begins his work with a critique of America's community college system. Although the relevancy and the need for liberatory education is obvious in Brazil in light of the blatant oppression in that culture, the need for liberatory methods in the United States is not as evident given that the oppression in the United States is not as apparent at first glance. Obstructions to critical thought, however, give rise to a need for liberatory methods and Shor explains some of them in Critical Ieaching and Everyday Life. Because liberatory learning is an exercise in consciousness growth, the obstacles to critical awareness require investigation according to Shor. Thus, Shor devotes his second chapter to criticizing numerous forms of overlapping and mutually supportive "false consciousness," such as reification, which is static and contained thinking characterized by hegemony. This phenomenon is perpetuated by institutions in everyday life such as the internal revenue service, the department of motor vehicles, and schools whose actions seem beyond human intervention. Rather than reacting 
to this way of life with change and criticism, the most that people feel empowered to do is "beat the system," a practice that keeps them in the system. Shor claims that "mass life in such a commodity culture involves a search for bargains, short-cuts, deals, hot goods, fire sales, close-outs, mark-downs, specials-of-the-day" (Shor, 1987, p. 59). A critical classroom, according to Shor, can combat reification by making ordinary routines the subject of inquiry, investigating economic laws, questioning the invulnerability of the system, and problematizing power in society. Acceleration, another aspect of culture that contributes to a lack of critical consciousness, refers to the everyday pace of life, a pace that Shor calls "dizzying." Minds are functioning at such a speed that deep and careful thought is rarely possible. Acceleration is thought to be the fault of the mass media, including radio, television, and print and is responsible for people exercising "shallow habits of mind." The technology that has accompanied twentieth century is also partially responsible for the congestion in modern culture. Mystifications, Shor argues, are distributed to falsify answers to social questions. Rather than being satisfied with cliches and other mystical answers, people should, instead, search for critical ones. Pre-scientism is yet another deterrent to awakening critical consciousness. Shor contrasts Prescientific thought with scientific thought. The latter he calls rational and demanding, the former, comfortable and familiar. Shor says, "Pre-scientism is magical; it is emotionally reassuring to minds which have been socialized to fear the use of their critical intelligence" (1987, p. 61). "Blind faith," "blind obedience," "common sense" do not require critical thought and perpetuate a powerless way of thinking. 


\section{Ieacher-student relationship}

In liberatory education, the teacher-student relationship is a dynamic one characterized by interdependence. Since the teachers and students work so closely together, it is important that they share a close relationship. Shor points out that "Liberatory teachers are not doing things for the students or to the students, but rather are launching a process with them ${ }^{n}(1987$, p. 113). As the learning process evolves, the relationship between students and teacher changes. As students emerge, the teacher recedes. This is a process similar to the government for which Karl Marx called. For Marx, the ideal political state is one that slowly loosens its reigns as its people gain the competence and confidence to take over. Just like the Marxist government "withers away" so does the teacher in a liberatory classroom.

Shor claims that alienation in mass culture is the largest learning problem. This divides students from each other and the instructor. Shor explains, "A complex process of self and social reconstruction is accompanied by unavoidable tensions" (1987, p. 116). The uneasiness caused by this phenomenon can be relieved by a valuable resource, comedy. Shor explains the benefits of laughter for the teacher-student relationship, "A comic atmosphere relaxes the fears attending desocialization. Further, comedy helps demystify the professional aura of the teacher. Through sharing humor with the class, the instructor comes down form the pedestal, in the process of withering away" (1987, p. 116). Other benefits of humor in the classroom include the bonding experience for people that it provides, the energy of play it fosters, and the reduction of sharp alienation of work from pleasure it encourages. 


\section{Learning_context}

In his discussion of teacher and student roles, Shor makes the point that the classroom is a special place. The learning environment can be described as one of symbolic separation which is discussed in the thematic dimension of Teachers and Student responsibility/roles. Part of the separation phase, according to Shor, involves the classroom itself. This allows for a unique place where learners can reflect on all aspects of life. The classroom is a place where students and teachers can "decelerate" from the fast pace of daily life.

The physical structure of a liberatory classroom is typically also very different from traditional ones. Shor's name for it is the "convertible classroom." Just like the liberatory teacher remains flexible to adapt to changing needs, so does the liberatory classroom. As Shor says, "Each mode fulfills a concrete developmental service: workshop, studio, skill and counseling center, consciousness-raising group, kiosk-news service, and library" (1987, p. 119). Shor prefers a round table milieu to the traditional class arranged in rows facing the teacher that he claims alienates students. He says. "In some cases where we cannot move chairs, I have simply sat in the rows to avoid having all eyes focused on a talking teacher at the front" (1987, p. 119).

As stated previously, social interaction which also contributes to classroom learning context can be explained by the rules that govern communicative behavior. The rules in liberatory classrooms differ greatly from traditional rules since the purposes in the two classrooms are different. Although both classrooms function to educate, they do so quite differently. While rules in a traditional classroom facilitate the transmission of knowledge, the rules in Shor's classroom are directed toward the creation of knowledge. 
For example, an important rule in liberatory classrooms is that all participants have an equal voice in the conversation. Another rule is that students help decide what subjects will be the focus of course content.

Goals

The long-term goal in a liberatory classroom is emancipation or empowerment, and the method by which students achieve this is critical thinking which can be thought of as a short-term goal. This is implicit in Shor's numerous descriptions of the lesson plans and activities he has tried in his college courses. One way that he does this is through "problematizing." This process involves critically analyzing something in the students' everyday experience from the desks they sit in at school to fast-food hamburgers they may eat at lunch. Students in the liberatory classroom help the instructor set the short-term goals because both share the power in the classroom.

Teacher and student responsibilities/roles

Additional responsibilities are placed on the teacher of a liberatory classroom, which include the need to democratize curriculum by discovering subject matter that directly affects student reality discovered through dialogue with the students. Since pedagogy must be situated in the learner's reality, it is essential for teachers to create intrinsic motivation by situating course content in the culture, language, and politics of the student body. Therefore, it is necessary that the instructor be an ethnographer in researching themes collaboratively with the students. Since instructors who utilize the dialogical process with their students hold the view that knowledge is a creation between people, they must be receptive to relearning. Liberatory theorists believe that teachers must realize they are not the sole possessors of knowledge, and that 
their view of reality is always limited and never complete. In addition, teachers need to be open to the possibility of change and should avoid mechanical and repetitious explanations. Through dialogue there should be an attempt to remake reality within every learning situation.

Identities of students and teachers depend upon a process that Shor calls the "object-subject switch." Keeping in mind the model of dialogue discussed in the preview to liberatory theory, "A with $B$ " refers to both individuals (teachers and students) as subjects. Shor believes this contrasts with traditional pedagogy which treats pupils as objects. As Shor says, "The teacher who changes to liberatory modes accepts responsibility for a process which converts students from manipulated objects into active, critical subjects" $(1987$, p. 97). It is the responsibility of the instructor to prepare for this process by researching student experience and problematizing the most important themes for students. Shor goes on to say, "The dramatic distinction between owning yourself or being owned involves a democratic or massified form of society, a humanized or de-humanized model of social relations" (1987, p. 98). This humanization process begins when each student maintains a role as subject. This process empowers students and can potentially liberate them. Another important element in the role of the liberatory teacher is the notion of "withering away" that involves separation, transformation, and reintegration of students. As Shor puts it "One goal of liberatory learning is for the teacher to become expendable" (1987, p. 98). The goals of self-regulating students requires that the instructor fade as students emerge. Since students in a liberatory classroom study everyday experience, it is necessary that students are able to distance themselves from the issue. As Shor says, "A reflective 
detachment on daily life is a means to push yourself away from the ordinary by pushing the ordinary away from you" $(1987$, p. 99). Another form of separation that takes place is the separation of the classroom itself in time and space from everyday routine which allows "it room to experiment with reflection on all aspects of social life" $(1987$, p. 99). A third form of separation has to do with the object-subject switch. Students remove themselves from a culture in which they act as objects and graduate from the liberatory class as subjects, a process necessary for liberatory growth. The separation process then leads students to their new responsibilities of systematizing, organizing, and analyzing their culture.

Teachers take on new roles as well, such as coordinator and peer discussant. Flexibility is crucial to the teacher's role. As Shor says, "Changing roles and operating at varying distances from the activity requires that the teacher pay careful attention to what's going on" (1987, p. 101). Although it is necessary that the teacher come to class prepared with an agenda, that plan redesigns itself while it is in progress.

Knowledge

Shor never explicitly discusses his theory of knowledge in this text. But his view is clear to the reader in the descriptions of course assignments that Shor explains. The collaborative nature of his lessons suggest that knowledge is created as a result of the social exchange among student learners in the liberatory classroom. In Critical Teaching and Everyday Life Shor outlines for the reader several examples of actual lesson plans from his teaching. In chapter seven, titled "Questioning Sexism: Poetry and Marriage Contracts," Shor explains how his class, starting with a poem, problematized marriage, 
reconstructed sex roles, and wrote their own marriage contracts. Shor says of the exercise, "Not only did we gain some command in a literary genre, but we also began to structure and re-structure reality from a feminist point of view" (1987, p. 222). This kind of knowledge gained through critical consciousness is virtually nonexistent in traditional classrooms perhaps because it would disrupt the routine behavior that supports the status quo.

\section{Power}

In liberatory classrooms, power is shared among teachers and students. The idea of students as knowing subjects implies they will share in the power of the classroom. The communication model endorsed by liberatory practitioners indicates the way that students, as subjects, are considered to be partners with their instructors although students can never achieve true equality. Throughout the literature on liberatory education, the reader will often see empowerment talked about as a primary goal of this method of education. Through the process of empowerment, teachers yield power to the students. When students leave their liberatory classrooms, it is the hope of their instructors that they take their power with them into society and its institutions. In the previously discussed thematic dimension regarding knowledge, the lesson involving marriage contracts illustrates the collaborative nature of a liberatory classroom as well as the importance of the student voice. In that lesson, students were given the parameters of an assignment and with some encouragement from their instructor, took charge of the class and came to new realizations about gender and relationships. The practical lesson is one that will likely affect the way they think about sex roles and marriage in their everyday lives. 


\section{Student relationship with peers}

The resource of one's peers is considered to be of great importance in a liberatory classroom. All of the projects detailed in Critical Teaching and Evenyday Life are collaborative in nature. Groups work together to edit each other's papers, to dramatize plays written by the students, to formulate marriage contracts that combat sexism, to invent a neighborhood constitution as part of a language project. From the beginning of his classes, Shor claims, "They [students] begin making bonds- some live in the same neighborhood, or are enrolled in the same programs, or have worked in the same places, or need rides to school, or announce their need for a job, which someone else may help out with" (1987, p. 129).

The role of peers in Shor's classroom is entirely in accordance with the liberatory philosophy. It is relevant to the way knowledge is constructed in that knowledge is created by all classroom participants rather than passed along from instructor to students. The social construction of knowledge relies on much interaction among classmates. It is in line with the way power operates in the classroom since students are encouraged to use their voice to communicate with each other as well as the instructor. The way peers interact is consistent with the liberatory communication model, which is discussed following the liberatory thematic analysis. Students' relationships with their peers affects their lives after they leave liberatory classrooms. Rather than leading fragmented lives, there exists a sense of solidarity with each other. This sense of themselves as members of a community can change the way they live and 
communicate with others in the workplace, in churches, social organizations, neighborhoods, and other groups to which they might belong.

\section{Evaluation}

For liberatory educators, the "ideal is for evaluation to be a learning activity consistent with the process" (1987, p. 112). Shor endorses selfevaluation and peer evaluation methods. This approach is in sharp contradiction to the traditional classroom which sees only the teacher as capable of determining how effectively students have mastered course material. Vehicles for measuring the democratic process of a liberatory classroom need to be determined by the instructor but the key is that the methods be appropriate. As Shor states, "A standardized testing instrument brought in from the outside, or designed by the teacher separate from the class, would only contradict the emergence of students as subjects" (1987, p. 112).

Shor believes that institutional testing by an empowered teacher is a way of keeping students oppressed as objects. In contrast, "By comparing the class' early, middle and late expressions, projects, dialogues, writings, interactions and component team-work, it is apparent what progress is being made in literacy and conceptual thought" (Shor, 1987, p. 112). This in-progress and inprocess evaluation is an extraordinary challenge to the ordinary shape of power in typical college classrooms.

\section{Thematic Analysis: A Pedagegy for Liberation}

A Pedagogy for Liberation is a unique book in many ways. In this text, Ira Shor and Paulo Freire model the dialogue that characterizes the liberatory teaching method. This "talking book" is an ongoing conversation between the two men on a variety of issues concerning liberatory pedagogy. The authors 
both recognized a need for this book after being asked certain questions repeatedly by teachers interested in utilizing liberatory teaching methods in their own classrooms. This book attempts to answer those and other frequently asked questions about liberatory teaching. In the introduction, the authors identify the benefits of a spoken book. Shor says, "When I write an education book at home by myself, I am closed off from an audience and I wonder if my words are meaningful. If I hear from others that my book reads as if I were speaking to them, I know I found the voice I wanted" (Shor \& Freire,1987, p. 3). Freire adds, "Another highly important aspect of doing a spoken book is that dialogue is itself creative and recreative...what happens here is that we stimulate the other to think, and to re-think the former's thought" (Shor \& Freire, 1987, p. 3). This meta-dialogue offers testimony to the benefits of a sociallybased pedagogy.

Ieacher-student relationship

One obvious advantage of the liberatory classroom is the relationship that the instructor and students share. According to liberatory analysis it is difficult if not impossible to maintain dialogue with others who are not members of one's social, economic, and cultural community. Communication in liberatory classrooms demands an attempt at equality so that everyone can participate as a co-learner. Although Shor and Freire do not discuss this thematic dimension specifically in A Pedagegy for Liberation, it is clear that the affiliation is influential in the student's learning experience. Clues to the type of relationship that exists between teachers and students in a liberatory classroom are evident in Shor and Freire's discussion of the dialogical method, the use of humor in the classroom and in their belief in the importance of researching the student's 
experience. Although these clues might indicate an ideal relationship exists between teachers and students, Freire makes the point clear that teachers and students can never be equals. Freire says, "The dialogical relationship does not have the power to create such an impossible equality...the educator continues to be different from the students...he or she cannot permit the necessary difference between the teacher and the students to become 'antagonistic" (Shor \& Freire, 1987, p. 92). This is one of the ways liberatory teaching improves upon traditional methods. In a traditional classroom, the teacher-student relationship is more likely to be antagonistic. The antagonism is heard clearly in the language that researchers use to talk about power, roles, authority, punishment in the classroom.

\section{Learning context}

The physical learning context is not discussed in A Pedagegy for Liberation. The other aspect of learning context, that which is defined by rules for social interaction is alluded to in both Freire and Shor's description of their classroom communication patterns. When traditional authority in the classroom is transformed, new rules become necessary. The active nature of a liberatory classroom creates an environment for learning that is highly participative for everyone involved. Unlike in a traditional classroom where the instructor and textbook remain sacred and unchallenged, the context in a liberatory classroom calls for a more critical attitude among students. Asking questions, offering examples, and disagreeing are safe behaviors in which students are encouraged to become engaged. 


\section{Goals}

Conscientization, or critical thinking, is the goal of liberatory pedagogy. Paulo Freire explains, "So, I am very much for demanding intellectual seriousness to know the text and context. But for me, what is important, what is indispensable, is to be critical" (Shor \& Freire, 1987, p. 11). For Freire, and for other liberatory educators, critical thinking is a recurring goal in daily interactions. This is in sharp contrast with traditional classes whose goal is to memorize the text. Freire argues, "We should not submit to the text or be submissive in front of the text. The thing is to fight with the text, even though living it..to engage in conflict with the text" (Shor \& Freire, 1987, p. 11). Later, Shor says, "The idea is to make critical reflection on society the fundamental activity" (Shor \& Freire, 1987, p. 86). When students are critical of their text, their society, and their reality, relationships between students, teacher, school and society are transformed.

By learning to be critical, Freire and Shor believe that students can liberate themselves. They say, "Liberating education is a social process of illumination" (Shor \& Freire, 1987, p. 109). Shor claims,"I want students to know that I speak not to bore them, not to exercise control, not to impose knowledge, and not to fill up the hour and earn my salary, but to communicate, to know something with them" (Shor \& Freire, 1987, p. 146). It is the hope of liberatory educators that once conscientization occurs, students are motivated to praxis, or the practical application of their knowledge to action. Action is so closely related to thought that knowledge is said to have not occurred without it. 


\section{Teacher and student respensibility/roles}

Since this text was written for teachers interested in liberatory education, there is a focus on the role of the instructor, whereas student roles are not elaborated in this book. "Liberatory education is fundamentally a situation where the teacher and the students both have to be learners, both have to be cognitive subjects, in spite of being different" (Shor \& Freire, 1987, p. 33). For Freire, this is the "first test" of liberatory education, that both teachers and students act as subjects, critically active in the joint search for knowledge. This deviates from the traditional classroom where instructors' roles include acting as the gatekeepers of knowledge. As Freire says, "We must avoid thinking that we are the illuminators. I think that liberating education implies illumination of reality, but the illuminators are the agents together in this process, the educators and the educatees together" (Shor \& Freire, 1987, p. 49). And as Shor says, "The teacher, then, is not an end-point of development for students to reach. The students are not a flotilla of boats trying to reach the teacher who is finished and waiting at the shore. The teacher is also one of the boats" (Shor \& Freire, 1987, p. 49).

Shor and Freire stress the importance of teacher as researcher in their spoken book. By researching, the authors are referring to listening to the students. Where do students come from? Where do they work? Play? What do they want? What do they know? How do they live? This practice became common for liberatory educators since Paulo Freire began teaching in Brazil where he felt that instruction was most effective when he used the building blocks of his student's lives. Shor explains, "I examine the words and themes 
most important to them so I will have reality-materials for the class studies" (Shor \& Freire, 1987, p. 9). The authors acknowledge that "This kind of grounded research has little market value in the academy. It's unfortunate because grounded intelligence is one thing teachers need to animate students. It is the base information for reinventing knowledge in the classroom" (Shor \& Freire, 1987 p. 9). In another passage Shor explains the effort required when speaking with students, an effort made necessary by division in language based on race, class, and sex, "In our discussions I would hear some words or phrases I didn't understand. Sometimes, l'd say sentences the students did not understand. So, I would stop the conversation to ask for an explanation of their language or to explain my statements to overcome the separation between us" (Shor \& Freire, 1987, p. 23). Without this attention to language, classroom talk ranges from intellectual idiom to the language of mass culture with little common ground for teachers and students. The authors talk about the importance of the liberatory teacher being a "mobile authority."

Shor and Freire explain the difference between teachers and students in a liberatory classroom. "The dialogic teacher is more intellectually developed, more practiced in critical scrutiny, and more committed to a political dream of social change" (Shor \& Freire, 1987, p. 95). The liberatory teacher is different not only by virtue of her or his training but also because the teacher leads a transformation that will not happen without him or her. The authors believe that democracy, freedom, and authority should be the practice of the liberatory educator.

The role of instructor in a liberatory classroom is a directive one. "That directiveness is not a commanding position of 'you must do this, or that,' but is a 
posture of directing a serious study of some object in which students reflect on the intimacy of how an object exists" (Shor \& Freire, 1987, p. 171). Shor explains, "I always try to relate to the students as cognitive subjects, as persons who are with me, engaged in a process of knowing something with me. The liberating educator is with the students instead of doing things for the students" (Shor \& Freire, 1987, p. 172). Again, the role of instructor is emphasized by Freire, "The liberating educator has to create by creating, in the very practice of teaching itself, learning the concrete limits of his or her action, getting clear on the possibilities, not too much behind our limits of necessary fear and not too far ahead" (Shor \& Freire, 1987, p. 177).

\section{Knowledge}

Liberatory educators view knowledge as an act, a constant process of creating and recreating meaning. This is vastly different from traditional education which views knowledge as a thing, objective and independent from human experience. Liberatory theorists believe that all knowledge should be challenged by teachers and learners, and this is done by extraordinarily reexperiencing the ordinary. Dialogue is the essential method of liberatory pedagogy and is closely related to a critical conception of knowledge. Dialogue is a process that can only be undertaken by subjects, not by objects; it is the essential method by which students and teachers go about re-experiencing the ordinary.

Knowledge is an important concept in every pedagogy. For liberatory theorists, dialogue cannot be separated from knowledge, for it is through the process of dialogue that knowledge comes to be and comes to change. In this 
dialogue with Ira Shor, Paulo Freire talks about the gnosiological (of knowledge) cycle which is worth quoting at length. Freire says:

The cycle of knowing has separate phases related to each other, and by seeing these moments we can understand better what happens when we try to teach or to learn. For example, if we observe the gnosiological cycle of knowledge, we can discern that there are only two moments in the cycle, not more than two, two moments that are dialectically related. The first moment of the cycle, or one of the cycle's moments, is the one of production, the production of new knowledge, something new. The other moment is the one during which the produced knowledge is known or perceived. One moment is the production of new knowledge and the second is one in which you know the existing knowledge. What happens generally is that we dichotomize these two moments; we make them separate. Knowledge is produced in a place far from the students, who are asked only to memorize what the teacher says. Consequently, we reduce the act of knowing the existing knowledge into a mere transference of the existing knowledge. And the teacher becomes just the specialist in transfering knowledge. Then, he or she loses some of the necessary, the indispensable qualities which are demanded in the production of knowledge, as well as in knowing the existing knowledge. Some of those qualities are, for example, action, critical reflection, curiosity, demanding inquiry, uneasiness, uncertainty-all these virtues are indispensable to the cognitive subject, to the person who learns! (Shor \& Freire, 1987, pp. 7-8)

Later, Freire explains the role of dialogue and its relationship to the knowledge process. He says, "Through critical dialogue about a text or a moment of society, we try to reveal it, unveil it, see its reasons for being like it is, the political and historical context of the material" (Shor \& Freire, 1987, p. 13). It is through this reconception of knowledge that liberatory educators hope to transform their students to be active, critical beings.

Power

As discussed previously, power in the college classroom is often operationalized as compliance gaining by a teacher. Shor helps explain why, "Education is much more controllable if the teacher follows the standard 
curriculum and if the students act as if only the teacher's words count. It [lecture] is the teaching model most compatible with promoting the dominant authority in society and with disempowering students " (Shor \& Freire,1987, p. 10). Often, power is utilized to "control" classrooms, but in a liberatory classroom, power is conceptualized differently.

By sharing power with the students in the liberatory classroom, liberatory educators hope to empower their students both inside and outside the classroom. Classroom work needs to be directly related to the transformation of society. One way instructors facilitate this process is by allowing students to choose the themes on which the class will focus. Liberatory educators believe that if teachers or students exercise the power to remake knowledge in the classroom, then they will assert their power to remake society" (Shor \& Freire, 1987, p. 10). And Freire adds, "And then, in the last analysis, liberatory education must be understood as a moment or process or practice where we challenge the people to mobilize or organize themselves to get power" (Shor \& Freire, 1987, p. 34).

Shor admits that not all students will be cooperative in their unique liberatory learning environment. He explains how his power can influence the unwilling students, "I look in the direction of the disruptive student and make eye contact and verbal contact to let her or him know I have noticed and want the disruption to stop" (Shor \& Freire, 1987, p. 127). If that behavior fails, Shor claims to talk with the student, and if the student continues, he may ask the student to leave the class. Shor says, "In some classes, there are small groups of disruptive students that I either expel or I ask to work alone outside of class" (Shor \& Freire, 1987, p. 127). 
Liberatory educators attempt to spread the power in the classroom by promoting a safe environment for all students to be involved. They encourage as many students as possible to take part in the classroom dialogue, but it is never a requirement. Shor says, "For them to feel pressured to speak even when they have nothing to add creates a false democracy" (Shor \& Freire, 1987, p. 102). The liberatory educators see opening dialogue with their students as an invitation, not manipulation.

Student relationship with peers

Students' relationships with peers is not explicitly discussed by Freire and Shor in A Pedagegy for Liberation.

\section{Evaluation}

Shor and Freire do not address the issue of evaluation in this dialogue.

\section{Communication and Liberatory Education}

This particular pedagogical theory is unique from the others discussed in this paper for the reason that the communication model is explicitly represented in one of the selected texts. In Critical Teaching and Everyday Life, Shor diagrams the model for dialogue, which can also serve as the liberatory communication model:

\section{DIALOGUE}

$$
\begin{aligned}
A \text { with } B= & \text { communication } \\
& \text { intercommunication }
\end{aligned}
$$

Shor describes the matrix that surrounds this horizontal relationship as "loving, humble, hopeful, trusting, critical" (1987, p. 95) and as two 'poles' exercising empathy engaged in a joint search. Shor calls this model "egalitarian and 
mobilizing" (1987, p. 95). If this communication model is one of dialogue, the one shown in chapter one of this paper can be described as "anti-dialogue" as Shor suggests. The matrix surrounding "A over B" can be described as loveless, arrogant, hopeless, mistrustful, acritical" (Shor, 1987, p. 95). All of the thematic dimensions discussed in this paper are affected by the way communication is modeled in the classroom, but some themes should be elaborated on here.

The way power is perceived in the classroom is greatly iniluenced by the dominant communication patterns among teachers and students. Power in the liberatory context is shared between subjects. Although Shor and Freire make the point that students and teachers can never be equals based on the nature of their relationship, they encourage a partnership between the two that is of equality with respect to voicing ideas, beliefs, opinions, and questions in the classroom.

It is the mode of communication in the classroom that transforms students from passive recipients of knowledge to creators of knowledge. Communication has great implications for an epistemological point of view. The liberatory communication model is consistent with the assumption that knowledge is a process of creating and recreating meaning. As Freire has mentioned, it is imperative that students take part in the two phases of knowledge in order for students to truly learn, rather than reducing the act of knowing to a transfer from teacher to student. It is students and teachers engaged in the act of dialogue that demands a critical attitude, an attitude which liberatory educators hope students continue to possess when they leave the classroom. Clearly, 
communication in the liberatory classroom has great implications for what it means to learn and to know both in and outside of school.

\section{Summary}

Liberatory educators believe that education is politics and that teachers should consider whose interests they represent in the classroom. They believe that traditional classrooms are delivery systems to market official ideas, not to develop critical thinking skills. Liberatory classrooms, in contrast are places where critical thinking is a prevalent goal. The content for lessons comes from real concerns of students' lives. Through dialogue, instructors and students engage in a joint effort of conscientization and learners enter a process of learning not by acquiring facts but by constructing reality in a social exchange with their instructor and peers. Students take part in both of the necessary steps of the creation of knowledge. Knowledge evolves from the interaction of reflection and action and occurs when an individual takes part in a transforming act. 


\section{CHAPTER FOUR}

\section{COOPERATIVE/COLLABORATIVE PEDAGOGY}

\section{Qvenview of Cooperative/Collaborative Pedagogy}

Wilbert McKeachie has said, "The best answer to the question, 'What is the most effective method of teaching?' is that it depends on the goal, the student, the content, and the teacher. But the next best answer is, 'Students teaching other students'" (cited in Johnson \& Johnson, 1988). Research on cooperative and collaborative learning emerges as another prominent alternative to traditional pedagogy. The cooperative/collaborative literature does not concern itself with a critique of the status quo to the extent that the literature on liberatory education does. Instead, this body of literature is more concerned with the effect of these teaching approaches, the philosophy that underlies them, and specific examples of classroom collaborative instruction. Cooperative learning is a structured, systematic instructional strategy whereby students assist each other in small groups while working toward a common goal and are individually accountable for the outcome. Cooperative learning is more than students simply working together in groups. This teaching style is predominantly emergent in elementary and secondary schools, and unfortunately, there has not been much research on cooperative/collaborative learning in college and university classrooms (Cooper, 1990).

Discussions of this teaching style often fail to distinguish between the terms cooperative and collaborative. Frequently the terms are used interchangeably, although, there is a difference between them. David and Roger Johnson, who have led the cooperative learning movement since the 1970s, present cooperative learning as a more structured and systematic form 
of collaborative learning. The term "cooperative learning," usually referring to elementary and secondary education, most often suggests that students are focused on reaching a common goal, whereas collaborative learning is more of an open-ended process that refers to the general process by which students work together whether in small groups or dyads. Some scholars, such as Bruffee (1984) suggest the goal of collaboration to be consensus. Unlike collaborative learning, cooperative learning emphasizes individual accountability, which requires that each group member be responsible for a body of information learned in the cooperative mode. This is necessary to prevent the possibility of some students doing all or most of the work. When all students know that they can be called upon to present the outcome, all must take part in arriving at the answer. One way to monitor this is by assigning the student an individual as well as a group grade for the task, or by testing students individually after the experience of group learning has taken place. The student's grade is almost always determined by individual tests and papers that are completed after a collaborative process has taken place. Collaborative learning, a more inclusive term, emerges as a philosophy that suggests knowledge is located in a community not an individual while cooperative learning is a technique based on the following principles: individual accountability, positive interdependence, heterogeneous groups, structured classroom activity, attention to social skills, and teacher as facilitator.

The notion of students teaching each other is as old as the time of Quintillian. However, the terminology used in the research is relatively recent. Bruffee (1984) claims that the term "collaborative" was coined and initial idea developed by a group of British secondary school teachers in the 1950 s. 
Although the Johnsons began writing about cooperative learning in the 1970s, Bruffee dates the beginning of a wide interest in collaborative learning in American college classrooms to be the 1980s. Bruffee notes that a group of educators during the Vietnam era sought to democratize education and it was through their political effort that collaborative learning became more widespread at the University of London. For American professors, the rise in interest of collaborative learning occurred in the 1970s in response to students' poor academic performance. Since then, collaborative methods have received more attention than ever, as educators continue to experiment with the method and encounter success.

Many teachers have said that the only way to really learn something is to teach it. Research on cooperative learning, which involves students teaching one another, supports the view of which teachers have long been convinced. In the research studies, cooperative learning is treated as the independent variable and most of the results are tracked either by measures of student learning or by teacher and student questionnaires. One advantage to cooperative learning versus traditional learning methods indicated in the research is student achievement (Bouton \& Garth, 1984; Johnson \& Johnson, 1990; Johnson, Maruyama, Johnson, Nelson, \& Skon, 1981; Sapon-Shevin \& Schniedewind, 1990; Slavin, 1983, 1990). For example, one study, involving college students, found that cooperative learning was consistently more effective than individual learning when students attempted to remember the content of a geology text (Dansereau, 1983). The research studies mentioned above also identified higher level thinking skills as a positive outcome of cooperative learning. 
Achievement effects are only one advantage of cooperative learning methods. Research also indicates that cooperative learning enhances students' affinity for one another, increases a positive attitude toward subject matter, develops collaborative competencies, enhances psychological health, and increases self-esteem (Johnson \& Johnson, 1988). Another potential advantage to collaborative methods in the classroom is the benefit of positive race relations among participating students (Kagan, 1986). Collaborative learning allows students the opportunity to develop positive bonds with students outside of their established friendships.

There has been a growing interest in the relation between collaboration and multicultural issues. Aronson (1978) was one of the first to address the issue in the 1970s with his concept of the Jigsaw classroom. His experiment with cooperation in the classroom grew out of the problems with desegregation, whereby students were competing, as Aronson says, "on unequal ground" (1978, p. 25). Aronson was equally concerned with the dysfunctional nature of the competitive American classroom as well as the ill-utilized pool of human resources (student experience and knowledge). Since Aronson, many scholars have taken an interest in the multicultural classroom. In his article "Cooperative Learning and Sociocultural Factors in Schooling," Kagan (1986) argues that cooperative learning, "holds the potential to provide educational outcomes far more positive than presently provided-especially for minority students" (p. 231). Kagan believes there are three pertinent problems presently contributing to a failure of the United States' educational system. The first is a failure to hold and educate minority students. Secondly, there exists a failure to successfully create positive race relations among students. Finally, there has been a failure 
to socialize students toward prosocial values and behaviors such as respect and care for others. Kagan acknowledges that cooperative learning is not a cure-all for the aforementioned failures, but he does believe this teaching method addresses these problems facing American schools. As Bouton and Garth (1983) argue, "The classroom learning group provides a unique context in which students can develop interpersonal skills" (p. 80). The group process increases complexity of interaction among students, and it empowers a greater range of behavior than a traditional classroom (Bouton \& Garth, 1983). Cooperative learning methods have been successful in reducing ethnic barriers and effects have shown that this way of learning also reduces a degree of rejection, increased positive interaction, and gained friendships (Adams \& Hamm, 1990).

Although areas of agreement far outweigh the areas of disagreement, Slavin (1990) points out that there is some controversy among researchers. One controversy consists of the debate between Slavin and the Johnsons over research methodology. Another concern is whether cooperative learning is effective at all grade levels, and scholars have called for more research in order to determine whether or not this is so (Slavin, 1990). Some scholars have questioned the appropriateness of cooperative learning for higher-order conceptual learning while others wonder whether group goals and individual accountability are necessary at the college level (Slavin, 1990).

Three texts have been chosen to represent this body of literature. Johnson and Johnson's Ceoperation in the Classroom addresses cooperative learning primarily K-12 levels. (The principles outlined in the Johnsons' text have been adapted to the college level). Bruffee's article, "Collaborative 
Learning and the 'Conversation of Mankind'," refers to collaboration in college instruction. The Johnsons systematically outline the features of this pedagogical alternative, and Bruffee's article concerns itself with the philosophical and epistemological issues that underpin this approach. Mouton and Blake's book, Synergegy, although targeted more for training programs, addresses collaboration among adult learners; therefore, their text is applicable to a college audience. Sknergegy is rich with examples of practical application as well as an outline of the alternative's key points.

\section{Cooperative/C.ollaborative Critique of Traditional Education}

This pedagogical alternative does not concern itself with a critique of traditional education to the extent that liberatory education does. However, part of the collaborative critique overlaps the liberatory critique with respect to a view of knowledge. Bouton and Garth (1983) describe traditional teaching practices as a "copy theory of learning" that assumes that students leave classrooms with a copy of the knowledge presented by the teacher. As the copy becomes clearer and more precise, the learning becomes more perfect. This perspective emphasizes teacher presentation and treats students as passive subjects. Mouton and Blake (1984) claim that this pedagogy "allows the efficient delivery of information," but that it also, "can induce passivity, apathy, and even active resistance from students" (p. 2). And they claim, "In its purest form, pedagogy induces compliance and obedience at the expense of student involvement and responsibility" (p. 2). Collaborative learning theorists have raised the question of what students are taught when their instructors endorse a pedagogy that stresses the individual as the prime agent of knowing. More often than not, when information is transmitted in a one-way process, it ignores the student 
voice while allowing the teacher to give an interpretation of reality as though it is objectifiable and beyond the scope of varying interpretations. In a critique similar to that of the liberatory school, Salmon and Claire claim that "Traditionally, school learning has been seen as the transmission of a body of knowledge-as teachers passing on their expertise to pupils" (1984, p. 1). Implicit in this practice of communication is the suggestion that what students learn is an impersonal body of knowledge that exists independent from student experience. For example, instructors often begin a lesson with the supposition that their students have no prior knowledge about the subject. As Salmon and Claire say, "This makes legitimate the separation of school knowledge from outof-school experience, and the exclusion from classroom concerns of personal feelings and personal relationships" (1984, p. 1). Advocates of cooperative and collaborative teaching methods find this separation particularly troublesome since many view personal relations to be a chief concern to educators.

The cooperative/collaborative critique of traditional education also questions the widespread presence of competition in American schools. Supporters of collaborative learning methods are often critical of the competitive nature of the traditional method. Kohn (1986) claims there are two primary modes of educating in American schools: competition and individualized learning. In this same view Kagan (1986) cites studies by Goodlad and Maller that support the notion that schools can be described as competitive, individualistic, and autocratic. Johnson and Johnson claim that for the past fifty years competitive and individualistic goals structures have dominated American education. David and Roger Johnson say, "Students usually come to school with competitive expectations and pressures from their parents" $(1988$, p. 5). 
Apparently this sentiment carries over to scholars at the college level, since Bruffee calls the American college classroom "that last bastion of hierarchy and individualism" (1984, p. 647). In research studies analyzed by Kagan (1986) competition has been found to discourage trust, dampen creativity, discourage risk-taking, produce anxiety, reinforce feeling helpless and powerless, encourage isolation, selfishness, alienation, secretiveness, and conformity. One way that collaboration differs from traditional learning, and claims to offer improvement, is that it encourages interdependence rather than competition. When collaborative learning methods are used, no fear of finishing last is likely to trouble students. Collaborative methods have been noted to encourage trust, heighten creativity, encourage risk-taking, reinforce feeling helpful, resourceful, and encourage interaction, sharing, cohesiveness, feeling valuable and valued.

There exists strong opposition to competition in classrooms. Kohn (1987) attempts to demonstrate in his article that defining one person's success at the expense of another's failure harms all students and Kohn cites several studies that indicate an inverse relationship between competition and achievement. Kagan (1986) identifies competitive and individualistic education practices as a primary reason for the lack of prosocial development among students. He makes a convincing argument that the lack of social skills will be even greater as we move toward a more technological world. "It appears," he says, "that the burden on prosocial socialization will increasingly shift from families and communities to the schools" (1986, p. 241). Salmon and Claire claim that this possibility seems "particularly significant in the context of innercity schools, where there is often mutual mistrust and hostility, across lines of race, class, gender, or academic ability" (1984, p. 4). 
Collaborative learning advocates do not see competition as a problem that will be easily solved, since this mentality is deeply rooted in our culture. American culture is very individualistic some argue, to a fault. The ideal self in American culture is thought to be independent and autonomous. Johnson and Johnson maintain that schools can be a starting point for cooperation, hoping that this way of learning reflects certain values that will in turn reach the business world (cited in Kohn, 1987). In America, it is considered a fault to be unduly influenced by others or to fail to separate from others. American businesses have already begun studying the implications of our individualist nature on performance in industry, and contrast it with the Japanese collectivist culture whose collaborative characteristics function to enhance performance in the world economy. In today's interdependent world, no people are as selfsufficient, self-reliant, and self-contained as America's prevailing ideology has tended to suggest. Collaborative learning methods are thought to relieve students of the fear and stress of competition.

Thematic Analysis: Cooperation in the Classroom

This text, written for the elementary and secondary school teacher, is a source of theoretical and empirical knowledge about cooperative learning. The characteristics of cooperative learning as defined by David and Roger Johnson in Ceoperation in the Classroem (1988) are generalizable to the college level, as these very techniques have been successfully adopted by college instructors (see Cooper, 1990). The Johnsons' book is based on the premise that the way students interact with each other as they learn has been "a relatively ignored variable in teaching" ( $p$. iv). The authors believe there are three basic learning situations, the first of which involves students competing with one another, a 
second, students ignoring each other and working independently, and the third learning situation exists with students working together cooperatively. Although the Johnsons believe there is value in all three situations, they devote Cooperation in the Classroom to the process of students working together cooperatively.

Teacher-student relationship

The teacher-student relationship is not discussed in Ceoperation in the Classroem. Much more emphasis is devoted to student's relationship with peers (discussed below).

Learning context

The physical context in a cooperative learning classroom is distinct from traditional classrooms for obvious reasons. If the goal in a cooperative classroom is to share ideas with peers and listen to the ideas of others, traditional neatly lined rows of desks is hardly functional. Instead, one is likely to find the cooperative classroom arranged with the desks in a circle or groups of small circles. This arrangement is conducive to the amount of peer interaction that takes place in a cooperative learning classroom. The Johnsons suggest that the way the teacher arranges the room is a symbolic message of what is appropriate behavior and that the physical arrangement of the classroom can facilitate the learning groups within the classroom. In a cooperative class, these authors claim that members of a learning group should sit close enough to each other that they can share materials, maintain eye contact with all group members, and talk to each other quietly without disrupting the other learning groups. And the Johnsons add that the teacher should have clear access to every group. 
The second aspect of context is that which is influenced by the function of social interaction. One of the more distinct characteristics of this learning is the amount of contact students share with their peers. Cooperative learning affords students the opportunity to get to know a group of students and to work with them toward achieving common goals. The increase in communication among students is largely responsible for the difference in context between traditional and cooperative classrooms. Traditional classrooms lack the sense of community that exists in a cooperative classroom. The rules in a cooperative classroom call for an environment in which the students assume a variety of distinct roles. For example, it is customary and encouraged for students to talk with each other while they work on assignments. This is in direct contrast to traditional classrooms where such talk would be discouraged, or perhaps a cause for punishment. Thus, the social context as well as the physical context differs in the cooperative classroom which is more social, more interactive, and calls for a different set of rules for classroom communication.

Goals

Instructors set the goals in the cooperative learning classroom. Cooperative learning requires that students are taught and encouraged to use interpersonal and small group communication skills. Learning social skills is emphasized as a primary goal of cooperative learning. Advocates of cooperative learning believe students need to be taught the social skills necessary to be productive members of their learning groups. Since many teachers believe that family and community have less impact on individuals' personal growth than in the past, instructors who advocate cooperative learning see the goal of helping students achieve their potential as effective citizens as 
crucial. Johnson and Johnson believe these skills may be those most important to one's future, with respect to employability, productivity, and career success. Interpersonal skills are not something that can be learned adequately outside the classroom so they should be taught as systematically as mathematics or any subject. Ideally, the skills are modeled by the instructor. One way these skills are taught is through group processing which is discussed under the thematic dimension "Evaluation."

\section{Teacher and student responsibility/roles}

The role of the instructor is discussed in great detail in Cooperation in the Classroom. Johnson and Johnson explain that the cooperative learning instructor is a technical/subject-matter expert as well as a classroom manager and consultant who promotes effective group functioning. They say, "The teacher structures the learning groups, teaches the basic concepts and strategies, and then monitors the functioning of the learning groups and intervenes to teach collaborative skills and provide task assistance when it is needed" (Chapt. 2, p. 3). This teacher as facilitator role conflicts with traditional classrooms where instructors typically assume total responsibility for all that goes on in the class. In the traditional role, the teacher gives students little room to experiment with ideas, deepen their understanding of concepts, integrate concepts into a coherent system, all processes necessary for understanding a subject matter.

According to Johnson and Johnson, the teacher's role consists of five major sets of strategies which include, 1) clearly outlining the objectives of the lesson ( specify academic and collaborative objectives, decide on group size); 2) grouping the students (arrange the room, plan materials, assign roles); 3 ) 
explaining the assignment to the class (explain academic task, structure positive interdependence, structure individual accountability, structure intergroup cooperation, explain criteria for success, specify expected behaviors, teach collaborative skills); 4) monitoring effectiveness of the groups and intervening to provide task assistance or to increase group skills (arrange faceto-fact interaction, monitor student behavior, provide task assistance, intervene to teach collaborative skills); 5) evaluating student achievement and helping students discuss their collaborative effort (evaluate student learning, process group functioning, provide closure). Each strategy is discussed in detail for prospective cooperative learning instructors. Several of them are elaborated here.

Characteristic of cooperative learning is the method in which groups are formed. The Johnson claim it is necessary that the instructor be involved in grouping the students, as students do not tend to group themselves in the most productive and beneficial way. Usually, when given that option, students will group themselves homogeneously. While instructors traditionally grouped students according to similar ability, the Johnsons suggest that this causes more problems than it solves. Heterogeneous grouping is thought to be important to each student's learning experience, and can be done based on ethnicity, gender, learning style, age, previous achievement, and other features determined by the instructor. This type of grouping can have a profound affect on all students' ability to accept, understand, and relate with people different from themselves. Cooperative learning has also been shown to help mainstreaming which involves placing heterogeneous students (in terms of handicapping conditions) in the same classroom. Mainstreaming has been 
shown to facilitate positive relationships among all students. It is the instructor's challenge to find as many dimensions for grouping as possible and to group students in a variety of ways throughout the academic term.

Another responsibility of the instructor is assigning roles to students. Cooperative learning groups involve shared responsibilities, meaning that a variety of tasks must be performed by group members. Some of the most frequently assigned group tasks include: Facilitator (organizes group, clarifies group's purpose, takes questions to the instructor), Checker (clarifies each group member's task, makes sure each agrees with group response and can explain it), Reader (reads problem to the group), Recorder (takes notes, records answers), and Encourager (offers support, elicits ideas from members, keeps the group feeling good about working together). Instructors are advised to see that students experience a variety of roles in their learning groups.

A primary characteristic of cooperative learning and one that distinguishes it from collaborative learning is the notion of positive interdependence. Creating positive interdependence emerges as a primary responsibility of the cooperative learning instructor. It is the instructor's task to see that students perceive that they are responsible for each other's learning within their learning group and that all pupils work together to produce a common product. This group identity can be achieved in a variety of ways. Mutual goals, division of labor, assigning students different roles, and joint rewards are all ways to ensure that students will believe that every member of the group depends on one another for its success. An advantage of establishing positive interdependence is that students do not feel as responsible to the instructor as they do to their classmates. Thus, students learn 
responsibility to peers, not to the teacher, and feel that their learning depends on every individual in their group.

Evaluating student achievement and helping students discuss their collaborative effort is another prominent responsibility of the cooperative learning instructor. This is called group processing and it is the final phase of a cooperative learning activity. During cooperative learning lessons, groups need specific time to discuss how well they are achieving their goals and maintaining effective working relationships among members. According to the Johnsons, "Such processing enables task groups to focus on group maintenance, facilitates the learning of collaborative skills, ensures members receive feedback on their participation, and reminds members to practice collaborative skills consistently" (Chapt. 6, p. 2). Group processing does not always follow the same format. The Johnsons claim that "Sometimes processing will be quite thorough and take some time. At other times processing will be quite brief" (Chapt. 6, p. 2). The procedures for the instructor's role in processing are: 1) decide what skills and behaviors the students will emphasize and teach the skills, 2) appoint observers, prepare observation forms, explain forms to observers, 3) observe and intervene when necessary, 4) have group members assess how often and how well they performed the collaborative skill, 5) have observer report to the group the information gathered and have group members report their impressions as to how they behaved, 6) have group members reflect on and analyze the effectiveness of their behavior by comparing their observed behavior with their own impressions of and expectations for their performance of the designated collaborative skills, 7) have group members publicly set goals for performing 
collaborative skills in the following session. Whether or not the instructor chooses to devote a lot of time to processing, the Johnsons believe that in some form, it is an essential element to the cooperative learning process.

Students' roles and responsibilities are not separately addressed by the Johnsons in this text. Student roles are implied in the discussion of roles and responsibilities of the cooperative learning instructors. For example, after reading the chapter that outlines the instructor's responsibilities and role for group processing, it is clear to the reader what the processing responsibilities are for the students in a cooperative activity. As mentioned before, students will assume a variety of formally designated roles in their groups. It is then hoped that students will transfer these skills to their lives.

Knewledge

No position on the nature of knowledge is discussed explicitly by the Johnsons in Coeperation in the Classroem. However, in the descriptions of specific lesson plans, it is clear that the Johnsons maintain an essentially traditional view of knowledge. For example, in one exercise, each student is assigned to read one of six paragraphs from a biography of a famous person, and then teach the content of the paragraph to the other five group members. All group members take their turns sharing the content of their paragraph and then each student takes a quiz that covers all six paragraphs written by the instructor. In other words, the knowledge in this lesson comes from a book and that which students are expected to know is determined by the instructor.

\section{Power}

Perhaps one of the most important responsibilities of the cooperative learning instructor is to share their power with the students. When the teacher is 
in control, their students' progress is in his/her hands. When the students assume more responsibility for their own learning, they are empowered to learn beyond the content of their instructor's lesson plans. This is an important message that the teacher of a cooperative learning classroom sends to students. People learn when instruction is embedded in a real, meaningfu! situation. Under these circumstances, learning is easy. Students learn best when they are motivated by their own desire to make sense of their world and to communicate that sense to others. If students and teachers can begin to redefine their roles in decision making about the classroom and the school, cooperative learning can become a mode of empowerment. It is the hope of these educators that there will be a transfer in students' power from the classroom to students' lives outside of the classroom.

\section{Student relationship with peers}

This is a predominant theme in the literature on cooperative learning. While the liberatory texts devote a good deal of attention to the teacher/student relationship, the cooperative literature focuses heavily on the relationships among students. The Johnsons say, "Students are expected to interact with each other, share ideas and materials, support and encourage academic achievement, orally explain and elaborate the concepts being learned, and hold each other accountable for learning" (Chapt. 2, p. 3). The authors emphasize, "Students are taught to look to their peers for assistance, feedback, reinforcement, and support" (Chapt. 2, p. 3).

Cooperative learning requires face-to-face interaction among students. Part of what makes this method unique is the oral exchange of class members. While traditional classrooms encourage "no talking in class," "no helping your 
neighbor," "Shhhh," and "do your own work," cooperative learning encourages talking and helping among the students. Pupils are encouraged to use their "twelve-inch voice" so they speak into their groups and the level of noise remains manageable. During the learning activities, students communicate to fellow group members that their learning depends on each other and their fellow students' communication skills. While many students may feel apprehensive about speaking in front of the entire class, and generally are reluctant to risk giving an answer that could be wrong, students tend to feel more comfortable expressing themselves in small groups where the risk is not so great.

Evaluation

Individual accountability is considered to be of primary importance for instructors formulating lesson plans for cooperative learning exercises. This means that each student is responsible for his/her own final grade after engaging in a collaborative process. The Johnsons state, "A criterionreferenced evaluation procedure will have to be used if the student is to receive a specific single grade; a norm-referenced evaluation procedure will undermine all cooperative and individualistic learning activities in the future" (Chapt. 4, p. 24). The Johnsons suggest several ways that the students' contributions to their peers can be incorporated into their final grade. For example, an individual score can be added to bonus points if all group members reach their goal; the individual score can be added to group average; the instructor can randomly select one group member's paper to score; or the instructor can average academic scores and add a collaborative skills performance score. 
Students need the opportunity to evaluate how well they are achieving their goals and the way students are employing their social skills to help the group function. This meta-analysis is called group processing. It requires the group member to focus on whether effective leadership, decision making, communication, and conflict management procedures are being used.

Processing questions are those such as, "How did your group get started on its task?," "How did your group reach agreement on your answer?," "How did working in a group help you?," and "How did you feel working in this group?" This self-reflection process helps students focus on the collaborative process and allows for feedback so students can improve their social skills in the groups across time. The cooperative learning group provides a situation that is rarely encountered, in which members work on a task and continuously reflect on how they are working together. This interaction provides a context in which individuals can both become aware of their own behavior and feel secure enough to explore and practice new behavior. When done appropriately, this part of the collaborative process can help to raise student self-esteem and teach social skills. The feedback takes the form of instructor evaluations as well as self-evaluations and peer evaluations.

\section{Thematic Analysis: Synergogy}

Mouton and Blake, authors of Synergegy have experience in education as well as industry although they are primarily noted for their leadership and management training. The title of their book comes from the combination of two Greek words, synergos ("working together") and agogus ("teacher"). Synergogy, therefore, means "working together for shared teaching" (1984, p. xii). Mouton and Blake contrast this learning method with two others, pedagogy 
and andragogy. Pedagogy has been previously described in this paper by the name "traditional pedagogy." Mouton and Blake call pedagogy "the most standard classroom model...where teacher teaches and learners passively absorb whatever they can" $(1984$, p. xii). Andragogy refers to adults teaching adults and is criticized for being situation-dependent and for its inability to codify or standardize information for mass use. These theorists claim that synergogy combines the best features of both of these methods and avoids their major drawbacks.

Mouton and Blake claim that there are three basic principles that promote educational success in a pedagogical alternative that they call synergogy, all of which have been discussed in the cooperative and collaborative literature. The first essential element to synergogy is direction. It is important that the learners are guided by an organized plan with specific instructions for them to follow in acquiring and enhancing new skills, attitudes, and knowledge. Secondly, this learning method requires teamwork instead of individual or group work in order to cultivate learner involvement and participation. A team differs from a group in that it has "explicit goals and objectives, tasks, procedures, and measured operational outcomes of its effectiveness" $(1984$, p. 11). The third feature of synergogy is the assumption that the whole has the potential to be more than the sum of its parts. Through teamwork, group members share knowledge, question one another's reasoning and assumptions, and examine the implications for their understandings. These processes result in in a higher level of understanding for all participants. Mouton and Blake claim there are many advantages to this paradigm, among them: the responsibility for learning is on the learners, learners and instructors describe it as fun, this alternative 
stimulates motivation, learners provide their own guidance, the method is a challenge to participants, and learners possess the ability to observe progress which prompts them to achieve more. They list the limitations as: it could be threatening to some teachers (giving up some of their power); there are fewer intrinsic rewards for students; there is a need to create designs and instruments of high quality which can be time-consuming for instructors.

Mouton and Blake present four designs for operationalizing synergogy in a work or classroom setting. The designs are not new to those familiar with the variations of cooperative learning. The Team Effectiveness Design is basically a lesson in reaching consensus and is recommended by the authors for group tests. Team-Member Teaching Design is known in the cooperative learning literature as the jigsaw method, whereby each member from one groups joins another "expert" group and returns to the original group to share his or her insight. The third variation, Performance Judging Design, requires learning participants to formulate their own criteria for performance. In the Clarifying Attitudes Design students complete an attitude questionnaire and proceed to share answers and rationales with group members. After discussion, students complete the questionnaire a second time to see if responses differ in light of their conversations with peers.

\section{Teacher-student relationship}

Mouton and Blake claim that "Our experience and research have led us to conclude that the relative ineffectiveness of current educational and training programs is an inevitable result of the character of the teacher-student relationship" (1984, p. 2). These authors believe that in traditional classrooms

and training rooms the teacher-dominated environment inhibits student learning 
and "sometimes leads to attendance and discipline problems" (1984, p. 2). Mouton and Blake believe that too much teacher authority blocks learning and that the teacher-student relationship can benefit from a shift in authority that results when teachers share more power with their students. They say, "Individuals who are struggling to assert their autonomy tend to resist the efforts of persons in authority to exercise control over them" $(1984$, p. 4). This is as far as the idea is developed, however, and the teacher-student relationship is not discussed further.

\section{Learning context}

The first aspect of learning context, the physical context, is not discussed by Mouton and Blake. The second aspect of learning context, or that which is influenced by social interaction, is only somewhat similar to the one described by the Johnsons. One difference is that the instructor plays a more low-key role in a synergogic setting. Mouton and Blake (1984) say, "learning teams operate under their own guidance, without a formal instructor to supervise or direct them" (p. 12). Apparently, these students are as highly structured but not as directly monitored as students in a cooperative learning classroom. The authors continue, "As a result, teams find themselves grappling with managing time, resolving differences between members, and facing other real-life choices and responsibilities" $(1984$, p. 12). A similarity in context between cooperative classrooms and synergogic setting is the peer interaction. Mouton and Blake say, "Education is an activity that takes place within the context of human relationships" (1984, p. xiv). 


\section{Goals}

Goals in a synergogic setting are set by the instructor. Since the primary audience for students of synergogy are adults who work in industry, the goals naturally are somewhat different from the public education system. The goals for a synergistic classroom vary, depending on the lesson. Typical goals may be knowing a product line, mastering a skill, or memorizing theorems, facts, or data.

One omnipresent goal of synergogy is motivation. Although this is mentioned as a benefit of cooperative and collaborative learning, it is not discussed as a primary objective. Mouton and Blake say, "At the heart of this issue [crisis in education] lies the topic of motivation: unless learners are adequately motivated they will not perform effectively, nor will they find learning rewarding or satisfying" (1984, p. 1), and "Many indicators suggest that our formal education system is failing to motivate students" $(1984, p .1)$. Chapter one of their text is titled, "Increasing Learner Motivation and Involvement."

Another goal of synergogy is to model real life situations. The authors say, "Synergogy provides a means for studying and rectifying many real-life problems related to attitudes as well as for acquiring skills requisite to the effective application of competencies in all aspects of an individual's life" (1984, p. 177).

\section{Teacher and student responsibility/roles}

In the first chapter of this text, Mouton and Blake outline the basic responsibilities of the instructor. The roles include: replacing their role as authority figure with learning designs and instruments managed by a learning 
administrator, enabling learners to become proactive participants who exercise responsibility for their own learning, applying to education the concept of synergy, using learners' colleague affiliations to provide motivation for learning.

The role of the teacher in this case, as can be seen under the thematic dimension of "learning context" is not as prescribed as the cooperative learning instructor. However, the authors claim, "In the effort to transfer responsibility to students, the teacher cannot simply abandon students to their own insufficient resources...although the resulting student involvement in learning situations may be high, the actual learning achieved may be minimal" $(1984$, p. 6).

One chapter is devoted to the role of the instructor in a synergogic setting. Chapter seven briefly discusses the different roles of a "learning administrator," a term that Mouton and Blake prefer. The authors outline several important functions as being supporting team effectiveness (deciding whether to intervene, deciding how to intervene), supporting individual effectiveness (dealing with poor individual preparation, poor attitudes toward participation, excessive dependency, and attrition), and creating teams (deciding on homogeneous or heterogeneous, size, self-selection). According to Mouton and Blake, the learning administrator need not be a credentialed teacher or an academic instructor.

Knowledge

Knowledge is not specifically discussed by Mouton and Blake. However, it is alluded to occasionally. For example, the authors say "Beyond the acquisition of knowledge, synergogy provides..." (1984, p. 177). One chapter is titled, "Acquiring Knowledge Through Mutual Deliberation: The Team Effectiveness Design." The authors also posit "Acquiring and integrating facts, 
and learning and applying principles are probably the most common activities in high school and university classrooms as well as in on-the-job business education" (1984, p. 7), and "Synergogy has proved itself to be a comprehensive approach that can be used in the acquisition of knowledge" (1984, p. xiv). This language suggests that they maintain a more traditional view of knowledge, by suggesting that knowledge exists outside of the learner and can be passed via people and textbooks.

Power

Sharing the power in the classroom is an important part of learning for Mouton and Blake. They say, "We see why the traditional model evokes passivity, resentment, and even hostility from learners" (1984, p. 5). They explain, "As long as teachers define their task as telling students what to learn, how to learn, and when to learn, they are likely both to impair students' motivation and to perpetuate the pattern of dependency"(1984, p. 5). Mouton and Blake see authority to be in the learning designs created by learning administrators. When learning administrators relinquish authority, these authors believe that students will automatically take a more active role in their learning and assume responsibility for it themselves. Mouton and Blake say, "If educators can create conditions that shift responsibility for learning from the teacher to the students, then there is no authority figure for students to rebel against" (1984, p. 5).

\section{Student relationship with peers}

Mouton and Blake stress one advantage of synergogy to be the way it makes the most of students' relationships with their peers. They see the peer relationship as a primary source of synergogy's motivating power. The authors 
believe that when the responsibility for learning is to one's peers instead of to the teacher, students are more apt to become actively involved in learning. "At the same time that the individual is resisting authority figures as sources of direction, colleagues are becoming a more important source of mutual reliance...friendships blossom, confidante relationships are established, groups and cliques form, and experiences of intimacy are shared" (1984, p. 4). The authors suggest that all the interaction among students is positive since they do not discuss any drawback of peer interaction.

\section{Evaluation}

Since Synergegy was written primarily for students of business workshops and training programs, evaluation is not stressed. Since a grade is not at stake, instructors who utilize synergogy are more concerned to know that students have mastered material. Although students of these synergogic designs are not graded, students may be given a test in order to measure their comprehension of information presented. Guidelines are provided for instructors for consideration when writing a test. These include suggestions such as "Identify a learning segment, identify key concepts, decide on the number of items, prepare item stems (opening statements that precede sentence-completion alternatives), write alternative answers, edit and revise questionnaire" (1984, pp. 25-26). These authors have formulated a method of scoring that involves individual and group scores and figures the mean learning efficiency score of each group. Mouton and Blake say "True-false tests are often used because they sample learners' knowledge more quickly than multiple-choice or essay test, although these can be used as welln (1984, p. 57). 
Critiques of teamwork are also utilized with this teaching method, similar to what cooperative learning instructors call "processing." Questions such as "Was he/she confident of the facts presented?" "Did he/she hold convictions when challenged?" and "Did he/she ask questions for clarification to ensure accuracy of understanding?" may be asked in evaluation of group members' effectiveness.

Ihematic Analysis: "Collaborative Learning and the 'Conversation of Mankind"'

Kenneth Bruffee's article, "Collaborative Learning and the 'Conversation of Mankind", " published in the journal College English, was intended to inform English teachers about collaborative learning. Bruffee believes that the literature on collaborative learning is not as clear as it should be and that many teachers are unsure how to use collaborative learning. As Bruffee says, "This essay is frankly an attempt to encourage other teachers to try collaborative learning and to help them use collaborative learning appropriately and effectively" (1984, p. 636). Bruffee offers a brief history of collaborative learning before discussing underlying ideas of collaborative learning in his attempt to "improve its practice and demonstrate its educational value" (1984, p. 636). One of Bruffee's primary arguments is the importance of community. His argument is informed by the work of Richard Rorty, who pioneered the notion of the social construction of reality. Bruffee's ideas evolved from Rorty's conception of "normal discourse." Normal discourse is based on Thomas Kuhn's term "normal science" and applies to conversation with a community of knowledgeable peers. Bruffee defines such a community as, "a group of people who accept, and whose work is guided by, the same paradigms and the same 
code of values and assumptions" (1984, p. 642). It is this view that guides his philosophy of many of the other thematic dimensions.

\section{Ieacher-student relationship}

This thematic dimension is not discussed explicitly in Bruffee's article except with respect to the change in authority (see thematic dimension "power").

\section{Learning context}

Physical learning context is not discussed in Bruffee's article. However, Bruffee gives the reader the impression that most of the time the class is arranged in a large group circle or smaller circles of four and five students for discussing peer editing. The second part of learning context, that which is influenced by social interaction, is clearly a primary focus of his essay. According to Bruffee, if one hopes to cultivate thought, one must cultivate community. Since thought and learning require community it is no wonder that more thinking and learning is assumed to occur by collaborative learning students. As Bruffee says, "Collaborative learning provides a social context in which students can experience and practice the kinds of conversations valued by college teachers" (1984, p. 642). Collaborative learning provides a unique community for college students, a community of peers. This is a realistic experience for students who upon graduation from college will join various communities associated with their various professions. Surrounded by peers, they will be expected to make decisions, act as leaders, solve problems and having had collaborative experience, students who are experienced with this type of learning environment should be comfortable with these expectations. Bruffee speaks to the importance of a learning community, "The first steps to learning to think better, therefore, are learning to converse better and learning 
to establish and maintain the sorts of social context, the sorts of community life, that foster the sorts of conversation members of the community value" (1984, $p$. 640).

Goals

One way in which the literature on cooperative and collaborative learning differs is in the goals of the pedagogy. While cooperative literature stresses the objective of teaching social skills, collaborative learning does not. This pedagogy does aim to encourage more students to join in academic discussion. Bruffee says, "Collaborative learning is an arena in which students can negotiate their way into that conversation" (1984, p. 647). Collaborative learning educators hope to include as many students as possible in conversation. He says, "Our task must involve engaging students in conversation among themselves and we should contrive to ensure that students' conversation about what they read and write is similar in as many ways as possible to the way we would like them eventually to read and write" (1984, p. 642). Bruffee says of his students, "The way they talk with each other determines the way they will think and the way they will write" (1984, p. 642). Apparently, Bruffee believes a primary goal of education is to prepare students to argue, debate, and discuss like their instructors do in order to prepare them for the next community of knowledgeable peers of which they will be a part. He says, "Mastery of a knowledge community's normal discourse is the basic qualification for acceptance into that community" (1984, p. 643).

Teacher and student responsibility/roles

Another significant difference between the literature on cooperative and collaborative learning exists with respect to the teacher's role. This is discussed 
in much greater detail by cooperative learning theorists. In cooperative classrooms, the teacher's role is specific and well defined. The literature on collaborative learning is not as specific and Bruffee's article is no exception. No specific roles or responsibilities of teachers and students are discussed.

\section{Knowledge}

Another significant difference between the literature on cooperative and collaborative learning is the way in which the two groups treat the theme "knowledge." Whereas knowledge is not dealt with directly by cooperative learning scholars, it is a primary focus of instructors of collaborative learning. And Bruffee has more to say about knowledge in this essay than any other thematic dimension. First, he makes the point that knowing is a social process. Bruffee says, "Knowledge is the product of human beings in a state of continual negotiation or conversation" (1984, p. 647). In an argument reminiscent of Paulo Freire's gnosiological cycle discussed previously in this paper, Bruffee comments on the role of communication in knowledge, "Reflective thought is public or social conversation internalized" (1984, p. 639) and "We think because we can talk, and we think in ways we have learned to talk" (1984, p. 640). Because community provides the opportunity for more communication, Bruffee calls on educators to cultivate community life in their classrooms. Bruffee says:

To think well as individuals we must learn to think well collectively-that is, we must learn to converse well. The first steps to learning to think better, therefore, are learning to converse better and learning to establish and maintain the sorts of social context, the sorts of community life, that foster the sorts of conversation members of the community value." (1984, p. 640) 
If one accepis the premise that knowledge is created by a community of "knowledgeable peers" then one's conception of learning changes as well. Bruffee claims, "To learn is to work collaboratively to establish and maintain knowledge among a community of knowledgeable peers...to learn is not to assimilate information and improve our mental eyesight" $(1984$, p. 646). If knowledge is something continually open to negotiation through conversation then learning occurs through a process, the name for which, Bruffee attributes to Richard Rorty, "socially justifying belief." Bruffee says:

We establish knowledge or justify belief collaboratively by challenging each other's biases and presuppositions; by negotiating collectively toward new paradigms of perception, thought, feeling, and expression; and by joining larger, more experienced communities of knowledgeable peers through assenting to those communities' interests, values, language, and paradigms of perception and thought. (1984, p. 646)

The importance of a learning community is introduced under the theme "learning context, " where the point is made that before one can think or know, a community needs to be established. Collaborative learning aims to facilitate the communities needed in an ideal learning environment. Since communities allow for the negotiation and transformation of knowledge, knowledge in a collaborative classroom is never finite. As Bruffee says, "Collaborative learning models how knowledge is generated, how it changes and how it grows" (1984, p. 647).

\section{Power}

The view of knowledge that accompanies collaborative philosophy challenges the way of which authority has been traditionally thought in college classrooms. Bruffee claims that teacher authority is derived directly or indirectly from participant's conception of knowledge. When one accepts the premise that 
knowledge is a socially constructed belief, the teacher is no longer thought to be the sole authority in the classroom. The teacher shares his/her authority with the students. According to Bruffee, "We derive our authority as teachers from being certified representatives of the community of knowledgeable peers that our students aspire to join" (1984, pp. 649-650). Collaborative learning places the roots of authority and power in the evolving dialogues within learning communities, rather than within hierarchic structures; therefore, collaborative learning models shared power in the classroom.

Student relationshio with peers

Given the emphasis on creating learning communities that consist of knowledgeable peers it is clear that students of collaborative classes share meaningful relationships with one another. Bruffee does not discuss "relationship with peers" in this essay.

\section{Evaluation}

Evaluation is not discussed by Bruffee in "Collaborative Learning and the 'Conversation of Mankind.' "

\section{Communication and Cooperative/Collaborative Pedagegy}

There exist more discrepancies in this body of research than in the previously analyzed liberatory texts. Though treatment of thematic dimensions is more fragmented, generalizations can be made about communication in the cooperative, collaborative, and synergogic classrooms. The first thing that can be said is that more communication occurs in these classrooms than in traditional ones. Since everyone takes part in the conversation, there is more shared meaning among class members. Both Freire and Bruffee make the point clear that knowing is a social process. If the purpose of education is so 
that students will know, then it follows that it is necessary to engage them in that process. Traditional education fails to engage students in the process of knowing. This alternative, however, is devoted to involving students in the epistemological process. The most widely accepted communication models in the field of speech communication stress the importance of two-way communication, and often the matrix is described as dynamic. However, in traditional classrooms, "communication" is primarily one way and the environment is hardly dynamic. Hence, what is known about communication is not reflected in most college classrooms. What is known about communication is reflected in cooperative and collaborative learning methods.

\section{Summary}

All three variations discussed in this section involve student collaboration. Collaborative learning is an alternative to the traditional style of learning in which the instructor is the sole authority and source of knowledge. Collaboration expects free, active exploration of knowledge, and as the thematic analysis reveals, this is stressed most heavily by the collaborative learning literature. In general, the cooperative/collaborative approach implies a democratic practice that shares with students the ability to determine the outcome of the lesson. It involves a constructive process and conflicts with the traditional notion of teaching as transmission of knowledge from teacher to student. In collaborative classrooms, it is assumed that learning occurs among group members rather than between a teacher and student. The cooperative and collaborative theorists raise an critique of traditional education and advocate a promising alternative. They have caused teachers to question traditional methods and the communication patterns of their pedagogies. 
Studies support the notion that when used systematically some of the time, cooperative learning increases student achievement and creates a positive attitude toward learning. As Salmon and Claire state, "Only by thinking aloud, acknowledging uncertainty, formulating tentative ideas, comparing interpretations and negotiating differences-only by these means can learners shape meanings for themselves and others, and therefore arrive at real understanding" (1984, p. 3). 


\section{CHAPTER FIVE}

\section{HUMANIST PEDAGOGY \\ Qvenview of Humanist Pedagegy}

The final pedagogical alternative discussed in this paper combines the perspective of feminists with Parker Palmer's spiritual view under the category "humanist." This series of readings is unlike the others discussed in this paper, because the works have not previously been grouped together under one heading. It is difficult to establish an appropriate title for this pedagogical alternative and no title is perfect; however, there are similarities that suggest the title "humanist." Feminists, in general, relate to the term humanist. Palmer (1983) calls himself a humanist. It should be stated that the humanists in this paper who represent contemporary communication-based pedagogies are different from more traditional humanists associated with the fields of psychology like Carl Rogers and Abraham Maslow and philosophy such as John Locke. Humanism traditionally regards humanity as the source and criterion of value and meaning. In the past, humanity in the sentence above was typically interchangeable with "the individual." More recently, however, humanity has come to mean "community." Ironically, traditional humanists have been criticized for being too individualistic. The humanists represented in this paper emphasize cooperation, the interdependence of human beings, and community, and therefore should not be linked with the sort of individualism associated with some early forms of humanism.

One of the themes of this body of literature is the ethical component of teaching. Palmer believes teachers should be devoted to finding the "truth" with their students. Noddings says, "Teachers, like mothers, want to produce 
acceptable persons-persons who will support worthy institutions, live compassionately, work productively but not obsessively, care for older and younger generations, be admired, trusted, and respected" (1988, p. 221). Noddings also says "The primary aim of all education must be nurturance of the ethical ideal" (1984, p. 6). And Belenky, Clinchy, Goldberger, and Tarule (1986) of Women's Ways of Knowing see women's development a primary aim of women's education. Belenky et al. see the development of women as going beyond intellectual development. They see epistemological and ethical development as equally important; which raises ethical implications for teachers.

As a rule, the literature on humanist pedagogy tends to focus on philosophical issues. In contrast to the liberatory and cooperative/collaborative literature, few specific, hands-on lessons or procedures are explained. Palmer purposely, it seems, avoids technique. Palmer acknowledges current pedagogical experiments and calls them "innovative and engaging ways to teach and learn." But, Palmer claims, "Most of them deal only with techniques. They leave the underlying epistemology unexamined and unchanged; they are not well grounded in an alternative theory about the nature of knowing" (1983, p. 30). Palmer believes that to find new ways of imparting knowledge, we must first find a new knowledge. In other words, to find a better medium we must find a better message. For Palmer, before any new technique is tried, it should be grounded in an epistemological and philosophical foundation.

The purpose of this pedagogical perspective is to raise issues for thought. It aims to bring to the forefront of teachers' minds fresh ideas for teaching and learning. A common thread in these readings is that knowing 
involves the whole person and is a highly personal and interpersonal process. Another characteristic that unites these theories is the belief that education exists so that students can find meaning. Parks (1986) says, "Meaning-making is the activity of seeking pattern, order, form, and significance" (p. 14). Parks believes that humans want to make sense out of things, to be oriented to their surroundings, to understand connections between things. It is in school that many students consider the questions as stated by Parks, "Why should I get out of bed in the morning?, What is the purpose of my existence and the existence of others?, Does anything really matter?, What can I depend on?, What can be trusted as real and what is my relationship to that?" $(1986$, p. 16). Humanists believe that higher education can assist with these questions or at least encourage students to ask them. The humanist perspective encourages thought about how religious themes and metaphors as well as feminine ones can inform our understanding of the education process, and therefore, communication in the classroom. In time, it is likely that this body of research will lead to pedagogical innovation; however, it has not quite reached that level.

A common theme of this pedagogical theory is the importance of community in higher education. Community is directly related to epistemology, in that knowing is an ethic, or a way of living. Palmer defines community as "a capacity for relatedness within individuals -relatedness not only to people but to events in history, to nature, to the world of ideas, and yes - to things of the spirit" (1987, p. 24). Palmer believes that other epistemologies such as feminist, Black scholarship, and Native American studies give hope for the future because they "enhance community by enlarging our capacity for relatedness" (1987, p. 25 ). Belenky et.al. stress connected knowing in their book as an 
important alternative to the more traditional separate knowing whereby students impersonally, autonomously, and objectively know something that is separate from themselves. In contrast, connected knowing stems from a relationship between knower and subject. All authors in this body of literature speak of a student's relationship with the subject as similar to a relationship one would have with a friend. Such a relationship is not one-sided, Noddings explains, "When we understand, we feel that this object-other has responded to us" (1984, p. 169). As Palmer (1990) states, "If it is important to get students inside

a subject, it is equally important to get the subject inside the student" (p. 13). He contrasts this notion with the traditional teaching method which he refers to as false objectivism. Palmer believes this objectivism "bypasses the learner's life story" (1990, p. 13).

\section{Humanist Critique of Traditional Education}

Most of the critique surrounding this perspective relates to tradition's conception of knowledge. This criticism, heard previously from liberatory educators, is elaborated by humanists. Palmer calls tradition "objectivism," and identifies its three traits. First, the academy is objective and in being so, distances the knower from the known. Secondly, objectivism is analytic which demands that academicians chop an object to pieces analyzing it. Finally, objectivism is experimental meaning that the scholars move dissected objects around. Palmer claims that this way of knowledge "breeds intellectual habits and spiritual instincts that destroy community" $(1987$, p. 22). By reducing the world to a collection of things, objectivism "places the knower in a field of mute and inert objects that passively succumb to his or her definitions of them. In this sense, " objectivism creates the most subjective of worlds" (1983, p. 56). 
Palmer claims that objectivism puts people in an adversary relationship with one another. "The oppression of cultural minorities by a white, middle-class, male version of 'truth' come in part from the domineering mentality of objectivism. Once the objectivists have 'the facts', no listening is required, no other points of view are needed" (1983, p. 68). One voice has clearly dominated education and that is the voice of the white male. This is particularly problematic for women, whose points of view are not heard in most traditional classrooms. This is a point made by the authors of Women's Ways of Knowing and is a major reason why the authors believe connected knowing is preferred by women; it allows women to include their experience in the process of knowing. Noddings claims that lecturing to large groups is not teaching. She says, "I cannot reveal myself through verbal symbols. I must explain, question, doubt, explore, revise, discover, err, and correct, but must also receive, reflect, and act." (1984, p. 113). For Noddings, teaching is both giving and receiving, a process not possible in the lecture mode.

In traditional classrooms, the focus is always outward whether it be nature, history, or someone's interpretation of reality. The reality of the classroom, teacher, or student is irrelevant or is not part of the nature, history, or reality. Knowing becomes a "spectator sport" and the classroom "a platform from which we view some subject," according to Palmer (1983, p. 34). Noddings, agrees, "A difficulty in mathematics teaching is that we too rarely share our fundamental mathematical thinking with our students. We present everything ready-made as it were, as though it springs from our foreheads in formal perfection" (1984, p. 8). Teachers do a disservice to their students when they fail to include them in the process of knowing. Noddings says of teachers, 
"We fail to share with each other the feelings, the conflicts, the hopes and ideas that influence our eventual choices. We share only the justification for our acts and not what motivates and touches us" (1984, p. 8 ). Classrooms should be places that are integral, interactive parts of reality. Palmer makes the point that the failure of the traditional conception of knowledge is not a problem of ethics, or the application of knowledge but rather in the failure of knowing "to recognize and reach for its deeper sense of passion, to allow love to inform the relations that our knowledge creates - with ourselves, with each other, with the whole animate and inanimate world" (1983, p. 9). Palmer claims, "Traditional classrooms are not a place for original inquiry but for imitation of authority, not a place of collaboration, but of competition between learners" (1983, p. 33). Palmer is not against lecturing, listening, and memorization, but he maintains that too much lecturing is "authoritarian," too much listening "unengaged" and too much memorization "mechanical."

Palmer also criticizes the competitive nature of traditional schools. He believes that a "collapse into expressive and competitive individualism" is responsible in part, for a collapse of virtue in society. He says, "the root fallacy in the pedagogy of most of our institutions is that the individual is the agent of knowing and therefore the focus for teaching and learning" (Palmer, 1987, p. 25). He explains that the typical flow of communication from instructor to student is a singular line that exists "for the convenience of the instructor" in contrast to "a complex web of relationships between teacher and students and subject that would look like true community" $(1987$, p. 25). He believes that when people carry the habit of competition into their world, they lack the capacity for building community. Palmer explains that a business school can 
offer a course in team management and collective work styles, but if the school requires the student to survive the class competitively then competition is the real lesson that is taught and learned. In response to these ills of education, this pedagogical perspective calls for empathy, caring, and love in the classroom.

Thematic Analysis: To Know As We Are Known/A Spirituality of Education

This text, as its title suggests, focuses primarily on a theory of knowledge. In the introduction Palmer says, "knowing draws not only on our senses and our reason, but on our intuitions, our beliefs, our actions, our relationships, and on our bodies themselves" (1983, p. xii). Palmer's perspective is unique to education. Parker Palmer is a social activist, a teacher and writer-in-residence at Pendle Hill, a Quaker spiritual community and adult study center near Philadelphia. He is a sociologist who left academics to pursue writing about his theories of community based on his personal experiences.

\section{Teacher-student relationship}

The teacher and student relations in a humanistic classroom are very unusual compared to teacher and student relations in a typical college classroom. Clearly, this more student-centered approach requires that the instructor devote more time and attention to being in touch with his or her students. Palmer says, "The teacher must value the students as potential friends, be vulnerable to the ways students may transform the teacher's relationship with the subject as well as be transformed" (1983, p. 104). Since Palmer believes there are "three parties to the conversation" which includes teachers, student, and subject, it is important that the teacher listen to the students as well as the subject at hand. Thus, Palmer's metaphor of friendship 
is carried further. He says, "The teacher, who knows the subject well, must introduce it to students in the way one would introduce a friend" (1983, p. 104). This atmosphere of friendship is considered healthy to student learning, but Palmer does not mean to suggest that the classroom must always be "sweetness and light." He explains, "The true test of a friendship is its ability to sustain conflict, its capacity to incorporate tension as a creative part of relationship; indeed, it is in tension and conflict that the transformations of friendship often occur" (1983, p. 104). Essentially, Palmer believes that the relations between teachers and students are a microcosm of the larger truth they wish to teach.

\section{Learning context}

More so than any theorist discussed thus far, Palmer stresses the importance of community in education. Perhaps it was living in the Quaker community at Pendle Hill that reinforced the notion for Palmer that learning cannot occur without community. For Palmer, the key to context is relationships. He says that reality is not defined empirically or rationally. Instead, "Reality's ultimate structure is that of an organic, interrelated, mutually responsive community of beings" (1983, p. 53). And "The deepest calling in our quest for knowledge is not to observe and analyze and alter things...it is personal participation in the organic community of human and nonhuman being, participation in the network of caring and accountability called truth" (1983, pp. 53-54). In order to grow and expand one's knowledge it is essential that he or she be a participant in a community. "Only in community does the person appear in the first place, and only in community can the person continue to become" (1983, p. 57). 
Certain qualities such as empathy, love, faith, mutuality and hospitality characterize the learning context of a humanist classroom. Palmer says, "Relationships of the self require inner understanding of the other, which comes from empathy; a sense of other's value, which comes from love; a feel for its origins and ends, which comes from faith; and a respect for its integrity and selfhood which comes from respecting our own" (1983, p. 53). To know the truth is to enter with our whole persons into relations of mutuality with the entire creation-relations in which we not only know, but allow ourselves to be known" (1983, p. 54). Hospitality must also characterize the learning space of a humanist classroom. Palmer claims that hospitality is an ethical virtue, but an epistemological one as well. "A learning space needs to be hospitable not to make learning painless but to make the painful things possible, things without which no learning can occur- things like exposing ignorance, testing tentative hypotheses, challenging false or partial information, and mutual criticism of thought" (1983, p. 74).

Palmer comments on the physical aspect of learning context. As one might expect, he is critical of the physical arrangement of the typical traditional classroom. He explains that "when the chairs are arranged facing the lectern, row upon row, the learning space is confined to a narrow alley of attention between each student and the teacher" (1983, p. 75). Such an arrangement says something to the students. Palmer explains, "In this space there is no room for students to relate to each other and each other's thoughts; there is no invitation to a community; there is no hospitality" (1983, p. 75). In contrast, when the desks are arranged in a circle, something different is conveyed. "The teacher may sit in the circle and talk, but we are all being invited to create a 
community of learning by engaging the ideas and one another in the open space between" (1983, p. 75).

\section{Goals}

Palmer quotes Thomas Merton, also a humanist concerned with love in teaching, who said, "the purpose of education is to show a person how to define himself authentically and spontaneously in relation to his world-not to impose a prefabricated definition of the world, still less an arbitrary definition of himself" $(1983$, p. 12). Palmer endorses this position of the goal of education. The search for truth is also prominent goal of education according to Palmer. He says, "The search for the word of truth becomes the quest for community with each other and all creation. The speaking of that word becomes the living of our lives" (1983, p. 49). He explains truth as something that is known in personal relationships, emphasizing his belief that knowing cannot be an individual process. Palmer says "We will find truth not in the fine points of our theologies or in our organizational alliances but in the quality of our relationships-with each other and with the whole created world (1983, p. 56). Palmer claims that personal truth does not lead to individualism but "toward a community of relationship, dialogue, and mutual transformation" (1983, p. 57). Ieacher and student responsibility/roles

The most important responsibility of teachers who wish to adopt this view of knowledge in their classrooms is to model the theory in practice. Palmer says, "If you want to understand our controlling conception of knowledge, do not ask for our best epistemological theories. Instead, observe the way we teach and look for the theory of knowledge implicit in those practices. That is the epistemology our students learn" (1983, p. 29). Palmer believes that the 
teacher is a mediator between knower and known. "A teacher is a living link in the epistemological chain. The way a teacher plays the mediator role conveys both an epistemology and an ethic to the student, both an approach to knowing and an approach to living" (1983, p. 29).

Similar to the liberatory theorists notion of re-learning along with the students, Palmer claims that the teacher should be a learner as well. "If we let our teacher-self speak without allowing our learner-self to listen and follow, our own truth will be broken" (1983, p. 64). This schizophrenia is an occupational hazard of teaching. Another guideline for teachers and students is to consider the human sounds of ideas and remember that words are spoken by a human voice. Palmer says, "Our opening question should not be "How logical is that thought?' but 'Whose voice is behind it? What is the personal reality from which that thought emerged? How can I enter and respond to the relation of that thinker to the world?'m (1983, p. 64). Palmer is emphasizing his point that knowing requires dialogue among teachers and students and that teachers must carefully listen to their students and empathize with their point of view.

In the opening quotation to this paper, Palmer was quoted as saying, "To teach is to create a space..." this sentiment reflects what he believes to be an important responsibility of the instructor, creating the proper learning environment. Palmer speaks to the climate of social interaction in a humanist classroom:

To study with a teacher who not only speaks but listens, who not only gives answers but asks questions and welcomes our insights, who provides information and theories that do not close doors but open new ones, who encourages students to help each other to learn-to study with such a teacher is to know the power of a learning space. (1983, p. 84) 
Palmer also goes on to explain the three essential dimensions of a learning space: openness, boundaries, and an air of hospitality. In order to facilitate openness the instructor can attempt to rid the consciousness and the classroom of distractions and obstacles that impede the ability to learn. To begin, the instructor needs to be comfortable with what he or she does not know. Palmer believes teachers' lectures are longest when they are least secure about what they are doing. Rather than filling the hour with meaningless words in an attempt to cover what they do not know, teachers should accept that they will have questions too. "If we can affirm the search for truth as a continually uncertain journey, we may find the courage to keep the space open rather than packing it with pretense" (1983, p. 72). Second, there must be boundaries to the open space. Learning space has structure, edges, perimeters, and limits that must be established with care. Finally, "because learning can be a painful place," the instructor should establish an air of hospitality. "Hospitality means receiving each other, our struggles, our newborn ideas with openness and care. It means creating an ethos in which the community of truth can form" (1983, pp. 73-74).

Another responsibility of the instructor is to make space for feelings. Feelings are part of the whole person and when suppressed, can inhibit one's ability to learn. Fear is a common feeling in classrooms where many students hesitate to ask questions, voice opinions, disagree with someone else. Emotional space in the classroom allows for more clear space in general. Palmer says:

The teacher needs to convey something like this to the students: 'This is a place where it is safe for your feelings to emerge. I have feelings too, and I will make myself vulnerable by telling you some of them. Teaching 
and learning are human enterprises, and we must use human emotions in the learning process rather than letting them use us. I will take the lead in this so you will feel encouraged to follow. I will try to respond to your feelings with an understanding that comes from knowing my own.' (1983, p. 86)

It is important that the instructor of a humanist classroom encourage students to accept this new role by modeling the risks involved. For example, Palmer says, "I may try to identify with my students by recollecting my own feelings when I was in the student role. I may invite them to speak with me, in or out of class, about the emotions that the course generates in them" $(1983, p .86)$. The instructor also has the responsibility of regulating the classroom conversation in order to involve as many students as possible. Palmer explains the way he limits student speaking turns so more become involved. He says, "The more aggressive and verbal students are checked and reigned. They are forced to sort and sift what they have to say, looking for that which is essential. The quieter, more retiring students suddenly find the space to speak" (1983, p. 80).

\section{Knowledge}

Clearly, Palmer's most prominent theme, knowledge, is the subject of much of his writing in this text. In chapter one he contrasts the origins and ends of two kinds of knowledge. He claims that through history, two sources of knowledge can be identified. One source of knowledge is curiosity which leads to control. Curiosity Palmer calls "an amoral passion, a need to know that allows not guidance beyond the need itself" $(1983$, p. 8). For Palmer, control is another word for power with a tendency for corruption. Another type of knowledge Palmer claims is drawn toward other ends. In contrast, knowledge born of compassion has the potential to contain as much fact and theory; however, it is traditionally drawn from spiritual heritage not intellectual tradition. 
Hence, knowing is loving. Palmer says, "In this education we come to know the world not simply as an objectified system of empirical objects in logical connection with each other, but as an organic body of personal relations and responses, a living and evolving community of creativity and compassion" (1983, p. 14).

To Palmer, knowing is spiritual because it is personal. Knowing is similar to the pursuit of a spiritual life that is deeply rooted in personal experience. One cannot study others' spirituality and know what it is to be spiritual. I think he is saying that knowing is like spirituality because one cannot memorize others' experience and truly know something. By the same token, knowledge is a personal process. In another passage that makes clear the highly personal process of knowing, Palmer says, "the images of self and world that are found at the heart of our knowledge will also be found in the values by which we live our lives" (1983, p. 21). Palmer believes that when capacities such as empathy, intuition, compassion, and faith inform the process of knowing "we pick up the world's subtle signals, its subvocal speech, its messages to us about our limitations and responsibilities and potentials" (1983, p. 54).

\section{Power}

Power is not discussed in detail in Io Know As We Are Known. However, Palmer suggests that power in the classroom can lead to corruption. It is clear given Palmer's view of knowledge that teachers do not possess all of the power in the classroom. The epistemology that Palmer endorses makes clear that students must share power and take an active role in their own education.

Student relationship with peers 
Since Palmer believes that the goal of education is truth and people find truth in their relationships with other people and the world, he believes the students' relationship with peers to be of vital importance in education. He believes that truth is found through dialogue between knowers and knowns. Also as stated under the thematic dimension of teacher and student roles, the relationship must be one of empathy, love, faith, and mutuality.

\section{Evaluation}

Palmer does not discuss evaluation in this text.

Thematic Analysis: "An Ethic of Caring and Its Implications for Instructional Arrangements

In this article educational philosopher Nell Noddings calls for the moral education of public schools. She believes that Education's concept of morality needs to be problematized and revised. She says, "Thus, I suggest that our forbears were right in establishing the education of a moral people as the primary aim of schooling, but they were often shortsighted and arrogant in their description of what it means to be moral" (1988, p. 218). Noddings calls for an ethic of caring in the classroom and distinguishes her conception from a more traditional view. She says, "Whereas Kant insisted that only those acts performed out of duty should be labeled moral, an ethic of caring prefers acts done out of love and natural inclination" (1988, p. 219). According to Noddings' theory, the teacher is the one-caring while the student is the one cared-for. Noddings' article, "An Ethic of Caring and Its Implications for Instructional Arrangements" is based on her book Caring (1984) in which she claims, "Apprehending the other's reality, feeling what he feels as nearly as possible, is the essential part of caring from the view of the one-caring" (1988, p. 16). This 
natural caring is a superior and more efficient state, according to Noddings, because it energizes both the giver and receiver. Caring is always characterized by a move away from the self. This ethic of caring arises out of agapism and feminism. As an ethical orientation, Noddings explains, caring has often been characterized as feminine because it "seems to arise more naturally out of a woman's experience than a man's" (1988, p. 218). Due to the brevity of her article, not all of the thematic dimensions are discussed. She regretfully identifies several topics she is unable to address in the essay "...the size of schools and classes, the goals of instruction, modes of evaluation, patterns of interaction, selection of content...cannot be discussed here" (1988, p. 219).

\section{Ieacher-student relationship}

The ethic of caring that Noddings calls for in her article, obviously greatly affects the teacher-student relationship. According to Noddings' the teacherstudent relationship is an asymmetrical one that exists between the "one-caring" (teacher) and the one "cared- for" (student). The one-caring responds to the needs, wants, and initiations of the one cared-for. "Her mode of response is characterized by engrossment (nonselective attention or total presence to the other for the duration of the caring interval) and displacement of motivation (her motive energy flows in the direction of the other's needs and projects)" (1988, p. 220). Ideally, the one cared-for reciprocates to the relation by recognizing and responding to the caring. For example, the student who enthusiastically pursues an assignment is responding to the instructor's caring. Since not all students respond as such, it is clear that the teacher-student relationship is often nonreciprocal. 
Noddings says, "When this ethical orientation is reflected on and technically elaborated, we find that it is a form of relational ethics " (1988, p. 218). She believes that a relational ethic is closely related to experience, "because all its deliberations focus on the human beings involved in the situation under consideration and their relations to each other" (1988, p. 218). She believes that an ethical person will always strive to see that a given relation is a caring relation. Noddings also claims that "Teacher and student must know each other well enough for trust to develop" (1988, p. 223). Teachers need to spend more time in direct contact with their students. She says, "If we cared deeply about fostering growth and shaping both acceptable and caring people, we could surely find ways to extend contact between teachers and students" (1988, pp. 224-225).

\section{Learning context}

Although physical context is not discussed by Noddings, she does advocate group work. Most of her article is devoted to arguing for an atmosphere of caring in the classroom. A setting must be established where moral education is possible. She says, "The object is to develop a caring community through modeling, dialogue, and practice" (1988, p. 223). The rules for social interaction also include free expression among peers in order to foster achievement and enhance social skills. As stated earlier, Noddings believes that the learning context is characterized by caring at every given opportunity for human interaction. 
Goals

Transmitting knowledge is not a goal ever mentioned by Noddings.

Instead, she believes in the goal of preparing students to be better equipped to deal with their futures. Noddings claims, "Teachers are concerned with their students' academic achievement, but, more importantly, they are interested in the development of fully moral persons" (1988, p. 221). She says, "A major teaching function is to guide students in a well-informed exploration of areas meaningful to them" (1988, p. 221). Because of this, students should aid in setting the goals of the class, "learning objectives must be mutually constructed by students and teachers," (1988, p. 221) an idea, she notes, that was recommended by Dewey in the 1930s.

\section{Teacher and student responsibility/roles}

When speaking of the mutuality of setting goals in the classroom, Noddings claims, "Teachers have an obligation to support, anticipate, evaluate and encourage worthwhile activities" (1988, p. 221). Being in touch with the students and knowing who they are is also an important responsibility according to Noddings. She says, "To shape such persons, teachers need not only intellectual capabilities but also a fund of knowledge about the particular persons with whom they are working" (1988, p. 221). Teaching is filled with caring occasions as well as attempts to avoid such occasions such as overuse of lecture, impersonal grading, and modes of discipline that lose the opportunity for moral education. It is the teacher's responsibility to use teaching moments as caring occasions. Fundamentally, the teacher role is to be the "one-caring" engrossed in the one-cared-for to enhance students' ethical ideal. Moral 
education, which should be the focus of the instructor of a humanist classroom involves modeling, dialogue, practice, and confirmation. All teachers, it is believed, can enhance the ethical lives of their students by modeling desirable ways of interacting with people. Noddings says, "Teachers model caring when they steadfastly encourage responsible self-affirmation in their students" (1988, p. 222). Dialogue is an essential element in the humanist classroom. Through the use of dialogue, problems are solved mutually and reciprocally. Practice is the third essential element for a caring classroom. According to Noddings, "In a classroom dedicated to caring, students are encouraged to support each other; opportunities for peer interactions are provided, and the quality of that interaction is as important as the academic outcomes" (1988, p. 223). Finally, confirmation is emphasized by Noddings as an important responsibility of the teacher in a humanist classroom. "The idea here is to shape an acceptable child by assisting in the construction of his ethical ideal" (1988, p. 223). And, "In education, what we reveal to a student about himself as an ethical and intellectual being has the power to nurture the ethical ideal or to destroy it" (1988, p. 224).

\section{Knowledge}

Knowledge is not discussed in this article.

\section{Power}

It is clear given what Noddings says about shared goals that humanistic instructors need to be willing to share the power in the classroom; however, this thematic dimension is not elaborated in this article. 


\section{Student relationship with peers}

Although this thematic dimension is not discussed with detail, it is clear that peer interaction serves an important function in a humanist classroom. Noddings believes that "Each of us is a relationally defined entity and not a totally autonomous agent. Our goodness and our wickedness are both, at least in part, induced, supported, enhanced or diminished by the interventions and influence of those with whom we are related" (1988, p. 222). Noddings believes that every human encounter holds the possibility for a caring occasion. Caring should be practiced not only between teachers and students but among students as well. She says, "The caring teacher also wants students to have practice in caring. In a classroom dedicated to caring students are encourage to support each other; opportunities for peer interaction are provided, and the quality of that interaction is as important as academic outcomes" (1988, p. 223). Evaluation

Noddings mentions that impersonal grading is bad, but evaluation is not discussed further in this article.

\section{Thematic Analysis: Women's Ways of Knowing}

This text, written by and for women, is devoted to explaining ways of knowing utilized and valued by women. The authors are responding to the work of William Perry who conducted similar research, but only studied the intellectual development of men. The theories presented in this text are the results of over one hundred of interviews with women of all ages who were asked to tell of their academic experiences in some detail. Most of the citations in this paper is taken from the last two chapters of the book, "Toward an 
Education for Women," and "Connected Teaching." Each participant in the research project, for example, was asked, what she thought would stay with her about her experience in school, to tell about specific academic and nonacademic experiences, about good and bad teachers, assignments, courses, and programs, what she thought has been most helpful about school, about things school did not provide them, about powerful learning experiences in and out of school, among other questions. After the transcriptions of the interviews were analyzed, some common themes emerged that the authors describe as "distinctively, although surely not exclusively, feminine" (1986, p. 191). The authors also found that when it comes to knowing, the methods used by women are not necessarily the methods traditionally valued by the status quo. These authors draw heavily on the critique of traditional education made by Paulo Freire of the liberatory perspective.

Teacher-student relationship

Like the liberatory classroom, the teacher-student relationship in a humanist classroom according to Belenky et al. is characterized by dialogue. As previously mentioned, these authors borrow some themes from the liberatory perspective. They endorse Freire's problem posing method that "invokes critical reflection by both teachers and students" (1986, p. 219). The authors say "Through dialogue, the teacher-of-the-students and the students-of-theteacher cease to exist and a new term emerges: teacher-student with studentsteachers" (1986, p. 219). The research findings of these authors suggest that the relationship between teacher and student can be very influential on women's learning. Women enjoy learning with a teacher with whom they feel at ease. 


\section{Learning context}

Like the other authors of the humanist perspective, Belenky et al. believe that the best learning context is a community. They say, "In a community, unlike a hierarchy, people get to know each other. They do not act as representatives of positions or as occupants of roles but as individuals with particular styles of thinking" (1986, p. 221). The classroom these authors endorse is a connected one. "The connected class constructs truth not through conflict but through 'consensus,' whose original meaning, Holland reminds us, was 'feeling or sensing together' implying not agreement, necessarily, but a 'crossing of the barrier between ego and ego,' bridging private and shared experience" (1986, p. 223). The connected class acknowledges that every individual has a unique perspective that is right by virtue of its existence and each truth is publicly available to all class members who stretch and share and add to themselves as knowers by participating in their classmates' ideas.

Physical learning context is not discussed, although the authors endorse group work where members of the group "must learn to know and trust each other" (1986, p. 118).

Geals

These authors see the goal of women's education to be intellectual, epistemological, and ethical development. They believe that education that occurs in the connected model "would help women toward community, power, and integrity. Such an education could facilitate the development of women's minds and spirits rather than retarding, arresting, or even reversing their growth" (1986, p. 228). Belenky et al. see women finding their intellectual voice as a major function of education. They see students and teachers together forming 
the goals for their learning. Connected teachers encourage students to pursue their interest in subject matters that excite them.

Teacher and student responsibility/roles

Belenky et al. use the metaphor of teacher as midwife which they contrast to the metaphor of the banker-teacher discussed in chapter three of this paper. They explain the need for such a teacher, "Many women expressed-some firmly-some shakily - a belief that they possessed latent knowledge. The kind of teacher they praised and the kind for which they yearned was one who would help them articulate and expand their latent knowledge" (1986, p. 217). The cycle for midwife-teachers is confirmation-evocation-confirmation. Banker teachers deposit knowledge in their student's minds while midwife teachers draw the knowledge out. Midwife teachers "support their students' thinking, but they do not do the student's thinking for them or expect the students to think as they do (1986, pp. 217-218). In contrast to lecturers, midwife-teachers focus on the student's knowledge rather than their own. "They contribute when needed, but it is always clear that the baby is not theirs but the student's" (1986, p. 218). Finally, midwife-teachers "help students deliver their words to the world, and they use their own knowledge to put students into conversation with other voices-past and present-in the culture" (1986, p. 219).

Even though students and teachers are partners in learning, " $\mathrm{A}$ connected teacher is not just another student; the role carries special responsibilities. It does not entail power over the students; however, it does carry authority, an authority based not on subordination but on cooperation" (1986, p. 227). Teachers can help their students by emphasizing "connection over separation, understanding and acceptance over assessment, and 
collaboration over debate" (1986, p. 229). Teachers can empower students "if they accord respect to and allow time for the knowledge that emerges from firsthand experience; if instead of imposing their own expectations and arbitrary requirements, they encourage students to evolve their own patterns of work based on the problems they are pursuing" (1986, p. 229).

\section{Knowledge}

The authors discuss five epistemological categories in this text, silence, received knowledge, subjective knowledge, procedural knowledge, and constructed knowledge. Much of this text is devoted to this topic, hence the title, Women's Ways of Knowing. Belenky, Clinchy, Goldberger, and Tarule speak most of the connected epistemology, a form of procedural knowledge that is certainly linked to the field of communication. Connected knowing allows the truth to emerge through care and is discussed in contrast to separate knowing which is based upon impersonal procedures for establishing truth. Connected knowing is based on relationships, not between persons but between knower and subject.

The authors report, "None of the women we interviewed wanted a system in which knowledge flowed in only one direction" (1986, p. 217) which helps explain the preference for connected knowing. In this form of knowledge, participants rely on personal experience as the most trustworthy form of knowledge and develop procedures for accessing other people's knowledge. The authors explain "at the heart of these procedures is the capacity for empathy" (1986, p. 113). If knowledge comes from experience, then in trying to understand another's knowledge one must try to share their experience. From this, it follows that since one can only approximate another's experience, one 
can only gain limited knowledge. Connected knowing implies not only that knowledge is constructed but that all knowledge is incomplete and tentative.

The authors explain the morality behind their epistemological theory, "People who experience the self as predominantly separate tend to espouse a morality based on impersonal procedures for establishing justice, while people who experience the self as predominantly connected tend to espouse a morality based on care" (1986, p. 102). Separate and connected knowing are not gender specific, the authors explain, but it is possible that they are gender related. "It is possible that more women than men tip toward connected knowing and more men than women toward separate knowing" (1986, pp. 102103).

\section{Power}

Power is not discussed in Women's Ways of Knowing, however, when one considers the teacher and student roles, it is clear that both share power in the classroom. Also, the authors, in the spirit of connected knowledge, stress the importance of instructors to encourage students to pursue the study of the subjects that interest them, or those to which they already perceive a connection.

\section{Student relationship with peers}

Since the type of knowledge preferred by these authors is connected knowledge that requires a relationship, peer interaction is very important. Since connected knowers attempt to gain access to others' knowledge, empathy plays an important role in their communication with others. The text claims, "Connected knowers learn through empathy" (1986, p. 115). The authors say, "Connected knowers begin with an interest in the facts of other people's lives, 
but they gradually shift the focus to other people's ways of thinking" (1986, p. 115). Belenky et al. claim "These encounters cccur with special frequency whenever women encounter people who hold and practice beliefs that seem exotic, intriguing, bizarre, alien, even frightening" (1986, p. 115). The text makes the point that many women see conversations with peers as a significant opportunity for knowing. One student interviewed claimed that "deep relationships offered her a chance to really get to know another view of the world" (1986, p. 115). Yet another came to view differently the purpose of a college education. The text reports, "She had thought the purpose of college was to prepare for a vocation; but then she began to believe that it was to train and broaden the mind" (1986, p. 115). Many women interviewed claimed the learning they experienced in the connected mode with peers took place outside of their classrooms, in informal conversations.

\section{Evaluation}

According to the authors of Women's Ways of Knowing, it is important that the instructor consider his/her method of evaluation carefully, for it has the potential to "subvert the aim of instruction" (1986, p. 208). The authors explain, "It is not evaluation per se that subverts the aim of instruction but evaluation in the separate (impersonal, objective) mode" (1986, p. 208). In contrast, evaluation in the connected mode requires that criteria and standards are developed through collaboration with students. Belenky et al. say, "Where impersonal standards are used, the students are turned into objects, and the connection between teacher and student is broken" (1986, p. 209). The authors claim that part of this problem of impersonal evaluation is due to white male dominance in education where feminine subjectness is abandoned for 
masculine objectness. To help cure this situation, the authors claim that, "In an educational institution that placed care and understanding of persons rather than impersonal standards at its center, human development might take a different course, and women's development, in particular, might proceed with less pain" (1986, p. 209).

\section{Communication and Humanist Education}

Of the three pedagogical alternatives discussed in this paper it is most difficult to explain the communication of the humanist classroom. Perhaps it is because the literature on this alternative affords its readers few examples of actual classroom discussion, unlike the other approaches discussed prior to this one. It is clear, however, that the learning context of humanist classrooms is significantly influenced by love, trust, confirmation, empathy, and care. These concepts can have an extraordinary influence on communication in the classroom. Although students are not likely to define it as such, when students perceive a teacher's love, trust develops and the student is more likely to take risks in the class and be more likely to speak up and share an opinion, ask a question, or disagree. Likewise, the process of confirmation builds student's esteem and empowers them to take more risks in communicating with their instructor and peers. Not only will more communication be the likely result of a learning context characterized by empathy and care, but the quality of communication is also affected.

\section{Summan}

The literature for this educational perspective supports the conclusions made by the last two areas of study, that learning occurs in relationships. This body of research makes a fresh contribution to instructional communication by 
looking more closely at those relationships and asking, "How can those relationships be improved?" Clearly, the teacher-student relationship is an emphasized theme in this area of study and the dynamics of the teacher-student relationship set the rules for social interaction. The rules in a humanist classroom call for attention to qualities such as care, love, and respect. This is a sharp contrast to the typical classroom characterized by competition, individualism, and hierarchy.

The authors of the representative texts chosen for this chapter indicate that there is a purpose to education that goes beyond the transmission of information. Education, in part, is responsible for preparing individuals for the communities to which they will belong in the future. The scholars agree that how students are taught will influence how they will live and that the kind of life they lead depends on the kind of people they are. Thus, instructors should take into consideration the pedagogy they endorse and how it affects the students in the classroom. 


\section{CHAPTER SIX}

\section{SUMMARY AND IMPLICATIONS}

The preceding chapters reveal that the three alternative paradigms differ not only in what they argue but in how they argue as well. Liberatory educators focus on the greater social ideals that are the motivating force behind this pedagogy. For that reason, Freire and Shor launch a harsh critique of tradition to establish a rationale for their alternative. Their political motives suggest that they hope for a more broad audience than the cooperative/collaborative and humanist scholars. Although they call on teachers to consider the political interests of their teaching, their argument reaches out to educational administrators, philosophers, and sociologists. As these authors guide the reader through their educational theory, the critique of the status quo is always present.

Cooperative/collaborative learning scholars cite empirical studies that suggest that the teaching method enhances academic achievement, students' affinity for school, the subject, each other, communication skills, etc. Most of the literature is very technique-oriented. The audience for this literature is primarily teachers of primary and secondary education or their teacher educators. The humanists represented in this paper represent various perspectives, which include philosophical, theological, and feminist influence. Nevertheless, they argue in much the same way and to a similar audience. Their arguments are directed toward individual teachers encouraging them to re-examine their purpose, rediscover the values that drew them to the teaching profession, and renew their idealism about teaching. 
After analyzing each representative text, a comparison of the three alternative pedagogies yields significant similarities and differences. Below, each thematic dimension is discussed to discover how these educational methods compare and contrast with one another, and how communication figures in each of them. The implications for the study of Instructional Communication are discussed. Finally, suggestions for future research are made.

\section{Synthesis of Thematic Analyses}

\section{Teacher-student relationship}

The teacher-student relationship that was found to be relatively insignificant in the lecture mode figures prominently in the alternatives discussed in this paper, particularly with liberatory and humanist methods. Liberatory educators endorse a "partnership" relationship between students and teachers. They see education as a process that teachers launch with their students, not for them. They recommend that instructors research students' experience in order to understand them and know them and discover what are the building blocks of their lives. The teacher of the liberatory classroom enters the students' world and makes the initial effort at establishing close rapport in the students' language. Dialogue, the vital method of liberatory education, functions to bring students and teachers into closer contact with one another and facilitates an increase of communication in the classroom as compared to typical classrooms.

Although cooperative/collaborative approaches implicate shared power in the classroom, this thematic dimension is not emphasized like it is by writers taking the humanist perspective. Instead, for cooperative/collaborative the 
sharing of power is more a by-product that results from the teacher-student relationship. Humanists represented in this paper devote a great deal of attention to the relationship between teachers and students. Consequently, this thematic dimension becomes a focal point in the literature. These authors call for a relationship characterized by love, empathy, trust, care and dialogue. They too, view this relationship as a partnership. Like liberatory educators, humanists advocate researching students' experience. In this perspective it is clear that the instructor is the more vulnerable of the two. Engrossed in his/her students, the teacher must feel secure with the asymmetrical relationship.

From the three perspectives analyzed in this paper, it is clear that a carefully nurtured teacher-student relationship has implications for student learning. It makes sense that in a bond of trust, students are more willing to take risks, and more students will find their academic voice in the classroom. Since some of the research indicates that a positive relationship is a particularly important factor for women in learning, more research should be done exploring the effects on both female and male learners.

Learning context

Both aspects of a learning context affect communication in the classroom. All of the pedagogical theorists discussed here agree that the traditional physical arrangement of classrooms is dysfunctional, inhibiting much opportunity for communication to occur. All of the authors introduced in this paper specifically advocate or imply that seating students in a large circle and/or in small groups are effective alternatives. To some degree, the second aspect of learning context, the rules for social interaction, are changed by the physical set-up of the classroom. The social exchange of students and teachers 
can also be enhanced by the instructor's effort to establish a particular climate in the classroom. Shor describes the classroom as a "special place" where students and teachers can decelerate from the hectic pace of everyday experience. Palmer endorses the creation of a hospitable place where empathy, love, trust, and mutuality are present. Noddings calls for an ethic of caring characterized by a teacher's engrossment in his or her students. All of the alternatives stress the importance of community in the classroom and the ability of community to enhance student learning. When a spirit of cooperation, cultural sensitivity, activity, empathy, and trust replaces competition, hierarchy, apathy, passive conformity, and mindless agreement the classroom is transformed to a learning environment where more students learn and more learning occurs.

\section{Goals}

Liberatory, cooperative/collaborative, and humanist pedagogies all contest the goal of traditional education, which is to get students to memorize a particular body of knowledge. This goal inhibits the achievement of each of the goals of the alternative pedagogies. Although each perspective contrasts with tradition on this thematic dimension, each has its own focus for the purpose of education. Liberatory educators see critical thinking, the development of a critical consciousness, and empowerment as the end of a student's efforts in school. Students assist in setting the goals for class. Cooperative learning theorists hope for students to enhance their social skills while they help each other learn course content and goals are typically set by the instructor alone. Proponents of collaborative learning are interested in developing critical thinkers as well. Bruffee suggests that a goal is to get the students talking like 
the teachers in order to prepare them for the next community of peers to which they will belong. Again, the teacher sets the goals. Finding meaning and a purpose in life, a sense of truth, becoming fully whole and moral people are among the concerns of the authors representative of the humanist perspective. This perspective suggests that students participate in setting some of the goals for their education.

Sprague (1990b) identifies four of the most common reasons for higher education: transmitting cultural knowledge, developing students' intellectual skills, providing students with career skills, and reshaping the values of society. It seems that the predominant method of instruction addresses the first, but neglects the last three of these important ideals. The alternatives discussed this paper, however address these aims more thoroughly. The three pedagogies are capable of transmitting cultural knowledge, although they do so differently from the traditional method. All of the methods claim to aid in developing students' critical thinking and reasoning skills. Similarly, all would agree that their method is capable of providing students with career skills, especially the cooperative/collaborative method. Likewise, all address the issue of changing society in some way. The liberatory authors see the ability to problematize and think critically to be ammunition for social change. They see a primary goal in teaching to be democratizing education and empowering students toward human liberation. Cooperative/collaborative educators perceive a possibility for change resulting from students' increased competence of social skills and a change in attitude regarding the values of interdependence over individualism and cooperation over competitiveness. Theorists who fall into the humanist category hope for a more caring citizenry that acknowledges the value of 
community and seeks truth and a sense of purpose in one's life. In addition, the liberatory and humanist perspectives believe schools should be a place where students learn what they most want to know, instead of what educators think they ought to know.

\section{Teacher and student responsibility/roles}

Central to any educational approach are the roles and responsibilities of teachers and students. In the traditional lecture method, the roles and responsibilities of teachers and students are very simple. The alternatives presented here challenge the typical dominance of teachers and passivity of students of traditional classrooms. The liberatory authors suggest that the ideal teacher is one who researches the students' lives, shares power, treats students as subjects, is flexible with lesson plans, and "withers away" when necessary. The cooperative learning instructor follows some clearly defined and specific responsibilities as defined by David and Roger Johnson. Both the cooperative learning instructor and the teacher described by Mouton and Blake become a sort of systems manager, rather than one intensely engaged with the students. Collaborative learning instructors' roles are not so well defined, but writers do focus on the obligation to create community in the classroom. Humanists see the teacher's responsibility as supporting, caring for and confirming the students. Belenky et al. use the metaphor of teacher as midwife to describe the instructor's function in the process of generating knowledge. All approaches would agree that students are not the only learners in the classroom, that teachers are learners as well. Rather than be frightened by this notion, teachers need to be secure with it. This change in roles breaks down differentiation between teachers and students. 
By far, the teacher's role is more thoroughly developed by these authors, as all texts reach out to a teacher-audience. For the most part, student roles are implied in the author's discussion of teacher roles. Student roles are not discussed in as much detail; however, one major distinction emerges in the literature of the three pedagogies discussed in this paper. The role of the student, traditionally passive, silent, and conforming is challenged. The "new" student assumes the role of partner with the instructor. Rather than sitting quietly in class copying a lecture, the student is active, alive, interacting with other students, sharing opinions, asking questions, perhaps challenging the instructor or the textbook. The students engaged in these alternative models are expected to accept some of the responsibility for their learning. This student role means more work for the teacher but can also provide them with more intrinsic rewards not possible in the traditional lecture method. It is gratifying for teachers to observe and be part of their students' growth.

Knowledge

Knowledge emerges as one of the most harshly critiqued and severely challenged thematic dimensions in this analysis. All three socially based pedagogies agree that the typical conception of knowledge-as a teacher's possession to be copied by students-ignores the student's voice and encourages compliance and conformity. Liberatory educators endorse the notion that knowledge is created by students and teacher through the social exchange of dialogue. This conception of knowledge empowers students and prepares them for political action. Thus, students participate in both the interpersonal and intrapersonal phases of knowledge, when it is both produced 
and perceived. In this view, knowledge is never separated from one's experience.

Cooperative learning theorists do not address epistemological issues directly, and when knowledge is referred to, a more traditional view is implied. in contrast, collaborative learning scholars emphasize the importance of a social exchange of continual negotiation among peers. Bruffee borrows the term "socially justifying belief" to help explain the collaborative nature of the production of knowledge in a community of knowledgeable peers. These somewhat incompatible views of knowledge between cooperative and collaborative learning theorists is one of the rare contradictions that exists within a single category in this thematic analysis. The epistemology of the humanist perspective is similar to the liberatory and collaborative scholars. These authors describe knowledge as organic, evolving, negotiable, very personal, and connected to one's relationship with the subject. Students actively participating in what they know creates a unique intellectual and social energy in the classroom as well as well as an increase in students' satisfaction of learning.

\section{Power}

All pedagogies represented here are critical of traditional power relations in the classroom and call for shared power among teachers and students. Liberatory theorists emphasize a partnership between the two while still emphasizing that teachers and students can never be equals. They stress empowerment as a primary goal, hoping that students will perceive themselves as powerful when they leave class. In cooperative and collaborative classrooms, teachers share some of the power and responsibility of the 
teaching; however, they maintain the power to set the goals. Mouton and Blake suggest that this shared power leads to fewer discipline problems and an increase in student motivation. Humanists do not emphasize this thematic dimension but implicit in these writings is an endorsement of shared power in the classroom.

\section{Student relationship with peers}

All three alternatives discussed in this paper differ from tradition with respect to students' relationships with their peers; furthermore, the perspectives on this thematic dimension coincide. The liberatory, cooperative/collaborative and humanist pedagogies all see peer collaboration as an important dimension in the classroom. Liberatory educators see group work as an opportunity for dialogue, for lasting relationships that are carried on outside of the classroom, and for shared teaching. Cooperative/collaborative learning relies on peer interaction for shared teaching. Indeed, it could be argued that in some forms of cooperative learning when the teaching is delegated to students, the teacherstudent relationship is neglected. Humanists see collaboration as an opportunity for dialogue, empathy, and caring occasions. Students who collaborate on projects and assignments feel a sense of responsibility to each other rather than to the instructor. This may account for low attrition rate in collaborative classes and students' reported excitement over these alternative classes. 


\section{Evaluation}

By far, evaluation is the most ignored thematic dimension of all authors. Half of the authors never addressed this essential element to the learning process, which is surprising given that most of them specifically challenge the traditional conceptions of knowledge and power in the classroom. The authors' failure to address the issue of evaluation is highly problematic to the instructor interested in trying the educational alternatives in his or her classroom. One cannot try a new teaching style very different from traditional lecture method and then fall back on traditional evaluation and grading styles. Belenky et al. and David and Roger Johnson are the only authors who emphasize that the mode of evaluation must be consistent with the educational practice. Belenky et al. endorse a system whereby students participate in developing criteria and standards with their instructor and assist with the evaluation, a procedure consistent with the process of collaboration. The Johnsons stress individual accountability and offer alternative ways for the instructor to combine a group as well as an individual grade. Shor mentions peer and self-evaluations but does not stress the notion of evaluation in his text. Mouton and Blake suggest simple testing ideas, but since they represent a traditional view of knowledge, the ideas are not useful to the instructor whose challenge is to evaluate in a method consistent with a collaborative process. One of the four of their models does involve students setting criteria for evaluation. Moreover, the widely used forms of evaluating the effectiveness of instruction-quantitative student ratings, one shot peer visitations-could well encourage some teachers to stick to traditional 
teaching methods since experimenting with an alternative poses a risk that students may reject the method and hold the instructor accountable.

\section{Dialectic Tensions of Alternative Pedagogies}

The educational perspectives discussed in this paper have been compared and contrasted with each other in order to discover the differences and similarities of three socially based pedagogies. Such knowledge may help the practicing teacher understand and experiment with different methods in the classroom. However, having the tensions artificially separated and displayed in a static way makes it difficult for one to conceptualize how each theory can be transformed into an actual classroom experience and how liberatory, cooperative/collaborative, and humanist perspectives might work together in one classroom. The following conversation demonstrates a hypothetical situation in which four teachers are gathered together one Monday afternoon in a "lunch bunch" meeting in the Communication Studies department of a small midwestern university. The instructors are discussing a concern of a probationary faculty member named Terry as a senior faculty member named Claire enters the room.

"Good afternoon everyone, what's on the agenda today?"

"Hi, Claire" replied Chris "We're talking about Terry's lower division courses. She handed out mid-semester evaluations today and she's worried about getting her ratings up before the end of the semester. Her tenure review committee meets the end of June."

"Yeah, Claire, I was hoping to get some insight from the senior faculty. I never imagined my ratings would be so low and I can't figure out what my problem is," said Terry. "I feel like I'm teaching them a lot and many of the 
students are doing very well in the course but the evaluations I read today show that they aren't enjoying the class much and they feel l'm doing an average job as their teacher."

"I understand your concern about teacher-ratings. They can cause you a lot of stress. I think they are valuable information for the beginning teacher, however, someone like Pat would tell you not to pay any attention to them, that they are set up by the powerful administration to reinforce the hierarchy of higher education. Where is Pat today?" asked Claire.

"He went across the street to 'Peanuts' to get a turkey club, he'll be back any minute. We probably don't want to get him started on this topic," said Chris.

"Yeah, you're probably right. Anyway, as I was saying" said Claire, " I think teacher ratings are a useful way for instructors to know how their students perceive the teacher-student relationship and the level of meaning students are achieving through the course."

"Well, isn't the purpose of teacher ratings to evaluate how effectively the teacher helps students master the material?" asked Terry.

"First, I'm curious about how you teach, Terry. Tell me about what you did today in class, for example," asked Chris.

"Well, we reviewed outlining for their next speaking assignment. I basically lectured right from the reading assignment for today. It should have been easy for them but they either weren't getting it or they were bored to death because their feedback was hardly encouraging."

"Have you ever experimented with other teaching methods?" asked Chris. "It sounds like you may rely too heavily on the lecture method in your 
classes which may cause competition for grades and apathy on the part of your students."

"Not really, I mean sometimes I have them work in groups but I was never taught how to teach. I've always lectured. That's how all of my classes were taught in college."

"Maybe you should try some collaborative learning activities in your basic course. I teach the whole basic course collaboratively." said Chris.

"What does that mean exactly, like how are your classes different?"

"Well, I like to think of my class as a community--that has resources, skills, talents, strengths, experiences, interests--all of which can be shared for the benefit of everyone in the class. Rather than students competing with one another, students work with and for each other."

"Why do you prefer this teaching method?" asked Terry, "What makes your class different?"

"I have experienced great success with collaborative learning. I prefer it because all of my students get involved in their learning. Almost every day there is a collaborative activity. Students feel a sense of responsibility to their peer groups. There are very few absences in my classes. The students enjoy being there; they like to participate. The active atmosphere is quite unusual compared to most college classrooms."

Pat walks in while Chris explains her feelings about collaborative learning.

"Isn't it difficult to structure every lesson in a collaborative way?" asked Terry. 
"Let me tell you it is a challenge to construct cooperative learning activities. They depend on the student's knowledge, skills, the length of the class period, and you always want to set aside some time at the end of the lesson to process the activity. You want the activities to have variety, you want to structure positive interdependence, individual accountability, homogeneous groups, etc. There is a lot to consider."

"Tell me for instance, Chris, how you would teach something like outlining in a collaborative fashion," inquired Terry.

"Well, you explained that you reviewed outlining today. I would have had each student come to class with a sample two-point outline including a thesis statement. I would break students into groups of five and instruct them to share their outlines with each other and critique each one as a group. After twenty minutes I would have the group choose one and share it with the class to see if the larger group has any further suggestions. As a larger group, I would review with the class the key principles of outlining based on the examples they present. You see, it's more interesting for me that way as well and I become more engaged in the process."

Pat interrupts, "There is the classroom manager for you, Coach Chris as her students like to call her. For the most part I believe in what you do, Chris, I particularly like the idea of socially constructing knowledge, but, if you don't mind me saying so, l'm skeptical of your role once the activities are set up. Sometimes I see you in your office while your students are in the classroom on their own. Also, the lessons seem very mechanized. Is there any room for spontaneity?" asked Pat in a challenging tone. 
"Well, perhaps you should sit in some day and observe a lesson in its entirety. There are times I leave the room on purpose to give the learners more space. They always know where to find me if they have questions, and believe me, they track me down when they need to," replied Chris. "Cooperative activities that are clearly planned out may not leave as much room for spontaneity but I try to be sensitive to that."

"But Pat has a point, doesn't he, Chris?" Claire interjected. "Some teachers could abandon their students with this method by misunderstanding their needs, or abuse the method by not caring about their needs and letting them work everything out themselves. That could be unnecessarily frustrating for students. I too, like the notion of socially constructed knowledge but I feel the teacher-student relationship in a collaborative class risks being detached and impersonal. All of the focus seems to be on peer relations. There is so much to be gained by both teachers and students from a caring relationship."

"Well, mother Claire, I suppose all of Terry's problems would be solved if she just loved her students more," retorts Pat.

"I don't think it would solve all of her problems but I think Terry and Terry's students could definitely benefit from more attention to the teacherstudent relationship, Mr. reductio ad absurdum. Perhaps if Terry confirmed her students so they know they are trusted to know and learn they would have a more positive outlook on the course. After hearing your criticisms of Chris's and my approach to our classrooms what do you have to say for yourself?"

"Not that we want to hear it again or anything, but for Terry's benefit, why don't you explain your approach, " adds Chris in a joking manner. 
"I think the most distinguishing feature of my classroom is the practice of dialogue, students and teachers engaged in the joint act of knowing. Students understand that in our classroom knowledge is something that is created among us and learning is a process of inquiry whose answers are open to negotiation. The equality among teacher and students motivates and empowers students and raises their aspirations in society," said Pat.

"It sounds like an unstructured bull session to me," challenges Chris. "Without structure, how do you ever cover a topic completely in a reasonable period of time?"

"Well, l'd like to encourage your own advice-come visit my class sometime, I welcome your feedback. I'm probably not as organized as you are but when the class is done I look back and feel confident that I've reached my goal for the class."

Terry, who has been silently listening to this conversation speaks up, "I really like the notion of an active exploration of knowledge. It sounds like students in all of your classes have to think on the spot. I feel like my students only think the night before the midterm and final. Hearing you talk about your classes makes me think that we really teach a lot more than one particular subject in our classes."

"You're right, Terry" said Claire, "I truly believe that how students are taught affects how students live and the kind of life they lead depend on the kind of people they are. We can influence what kind of people our students are in a caring classroom. We can help them experience the joy in relating to others and the joy in the quest for understanding." 
"We can empower them with the thinking skills to make changes in their lives that affect them and others," said Pat.

"We can teach them communication skills in the way we structure activities and teach them to value cooperation over competition and interdependence over individualism," added Chris.

"And prepare them for the communities in which they'll live," Claire smiles.

"Boy, am I feeling simplistic, what about the full sentence outline? I guess my goals aren't as ambitious as yours?" Terry asked the others.

"A lot of teachers, especially those who think about their profession," said Pat, "have hidden agendas." It's important that the so-called "greater goals" don't interfere with the short term goals of your class, such as teaching your students how to outline, which is important. That too, can affect how they think and really make a difference. Skills can empower students. Without the skill to apply their knowledge the knowledge is for naught. Students absolutely need to be taught action as well as knowledge."

"I can really see the importance of flexibility in your classrooms. I can see each of your approaches working together in one classroom at the right time and place. No alternative in its extreme form is efiective, but I think all of you have a legitimate approach that adds something exciting to an ordinary classroom. I have so much to think about. Please excuse me while I go temper my genius."

Terry hurries out of the lunch bunch meeting while the senior faculty continue to debate their perspectives. 
In the preceding conversation, a number of important points are raised. Terry is correct in declaring that none of these alternatives in its extreme form is effective. It is true that teachers teach more than a particular subject by their teaching methods. Teachers do have the power to influence the way students perceive knowledge, learning, thinking, and the tensions between competition and cooperation and interdependence and individualism. It is possible that all three alternatives work together in one classroom. A good teacher knows how to balance different techniques and philosophies. It is essential that a good teacher develop a sense of timing for these and other options in the classroom.

Dialogue among educators such as the collaborative effort of Terry, Chris, Claire and Pat is essential. Such cooperation opens new ideas for educators, encourages pedagogical innovation, and forces teachers to think about how they teach and how the way they teach influences their students. Conversations such as these encourage educators to question the basic assumptions of education, knowledge, and in general, the status quo. These collaborative efforts also help educators discover the learner within the teacher. When communication in the classroom is thought about in a deeper way, the experience is richer for teachers and students. This idea has implications for teachers and teacher educators who should be encouraged to think about communication in a more contemporary fashion. Lecturing at future teachers in teacher education courses only socializes them to one of the least effective models of teaching. Teacher educators should expose their students to more sophisticated models of communication by demonstrating them in their classes. 
Implications for Instructional Communication

Teachers legitimize classroom communication patterns through the pedagogies they endorse. The socially-based alternatives discussed in this paper advocate a more broad communication model than the traditional method endorses. According to current definitions of communication, the transmission of information that takes place in traditional classrooms can hardly be considered communication. That model leaves very little room for feedback, discussion, debate, comments, questions, and critical thinking on the part of the students. Students remain passive while their instructors dictate what is to be known (memorized).

In contrast, in collaborative classes, students assume the roles associated with assertive communication by sharing opinions, expressing feelings, asking questions for clarification, and acting as the leader of a group, among other behaviors. In liberatory, cooperative/collaborative, and humanist classrooms, the proper context is created for students' active participation. Authors represented in this paper assume that students' experience with a wide repertoire of communication skills will become practice for them as they leave the classroom. Thus, students' competence of leadership, decision making, listening, and other communication skills is enhanced in all of their classes, rather than simply their basic oral communication course.

\section{Suggestions for Future Research}

The thematic analysis of three socially based educational alternatives yields many questions that remain unanswered. How is student success enhanced by using liberatory, collaborative, or humanist pedagogies at the 
college level? Do the strategies of these methods improve critical thinking skills? How? How do the alternatives affect academic standards? What skills, attitudes and behaviors need to be changed or improved to enhance teaching with these methods? How do the collaborative methods of the alternatives affect social interaction inside and outside of the classroom? Is this important? Why? What values are learned or changed when students work in small groups of a humanist classroom? Does the use of collaborative learning mirror the real world (quality groups, work teams, committees, etc)? Are the alternatives effective across disciplines? What attitudes, values, and practices within the institution impede the implementation, growth, acceptance, or success of innovative pedagogies?

As noted, a major gap in the literature exists when it comes to evaluation procedures. Grading and evaluation procedures need to be addressed by liberatory, collaborative, and humanist scholars. More studies should be done involving women and learning styles, and studies should involve men as well in order to determine whether or not there is a relationship between gender and preferred learning methods. The studies of cooperative/collaborative methods in secondary and higher education are extremely disproportionate. More research on collaborative learning should be done at the college level. To this reader's knowledge, there have been no ethnographic studies of the communication in liberatory or humanist classrooms. In addition, teacher interviews would be an interesting way to inform other teachers the risks and benefits of educational alternatives.

The thematic dimensions discussed in this paper: teacher-student relationships, the learning context, what the goals are and who sets them, the 
responsibility and roles of both teachers and students, epistemology, grading procedures, the power relations, students' relationship with peers, as well as the degree to which a pedagogy is teacher/student centered, all contribute to the means by which schools make contributions to the consciousness of students and to the store of public knowledge, public values, and public culture. Teaching practices consistent with contemporary theories of learning are needed to prepare students for life after school.

There are many answers to the question "What is learned in school?" The authors represented in this paper have explored that question and realized that what is learned is more than information about a particular subject. The obvious answer is the knowledge students gain about the world, history, geography, mathematics, English, and their other academic studies. But students can and do learn more than knowledge of particular disciplines. Schooling also contributes to the acquisition of communication skills. Typically, individuals learn these skills in the family, and later in their careers. For many people, college bridges the gap between these two periods in one's life. The school also provides a larger social aggregate in which people form various associations, and thus spend a good deal of time learning how to get along with, work with, and learn with others. Schools provide students with experiences and opportunities largely unavailable in other social settings. Educators need to recognize and take advantage of these opportunities. Of course it is important to understand that a single teaching method is not appropriate for all instructional objectives; however, research suggests that how we teach is what we teach. If educators consider that a great part of their purpose is to prepare students for responsible citizenry, then cooperative and 
collaborative, liberatory, and humanist teaching methods may be something all teachers at all levels should consider using in their classrooms. 


\section{References}

Adams, D. M. \& Hamm, M.E. (1990). Cooperative learning: Critical thinking and collaboration across the curriculum. Illinois: Charles $\mathrm{C}$. Thomas.

Allen, R. R., Wilmington, S.C., \& Sprague, J. (1991). Communication in the secondary school: A Pedacogy. Scottsdale, AZ: Gorsuch Scarisbrick.

Apple, M. W. (1989). Teachers and texts. New York: Routledge.

Aronson, E., Blaney, N., Stephan, C., Sikes, J., \& Snapp, M. (1978). The jigsaw classroom. Beverly Hills: Sage.

Barrow, R., \& Woods, R. (1988). An Introduction te philosephy of education. New York: Routledge.

Belenky, M. F., Clinchy, B. M., Goldberger, N. R., \& Tarule, J. M. (1986). Women's ways of knowing: The development of self voice and mind. New York: Basic Books.

Bottomore, T. (Ed.). (1983). A dictionary of Marxist thought. Cambridge: Harvard University Press.

Boutan, C., \& Garth R. Y. (1983). Learning in Groups: New directions for teaching and learning. San Francisco: Jossey-Bass.

Bruffee, K.A. (1987). The art of collaborative learning. Change: The Magazine of Higher Learning, 19, 43-47.

Bruffee, K.A. (1984). Collaborative learning and the "conversation of mankind." College English, 46, 635-652

Bruschke, J., \& Gartner, C. (1991). Teaching as communicating: Advice for the higher education classroom. Journal of Applied Communication Research, 19, 197-217.

Cooper, J. (1990). Student involvement in learning: Cooperative learning and college instruction. Jeurnal on Excellence in College Teaching, 1, 16-27.

Daly, J. A., \& Korinek, J. T. (1980). Instructional communication theory and research. In D. Nimmo (Ed.) Communication Yearbook 4 (pp. 515-531). New Brunswick, NJ: Transaction Books.

Dansereau, D. F. (1983). Cooperative learning: Impact on acquisition of knowledge and skills. (Report No. 586.) Fort Worth, TX: Texas Christian University, U.S. Army Research Institute for the Behavioral and Social Sciences. (ERIC Document Reproduction No. ED 243 088). 
Freire, P. (1970). Pedagogy of the oppressed. (M. B. Ramos, Trans.) New York: Herder and Herder.

Freire, P. (1985). The politics of education. Massachusetts: Bergin \& Garvey.

Freire, P. (1987). Education for critical consciousness. New York: Continuum.

Friedrich, G. (1989). A View from the office of the SCA president. Communication Education, 38, 297-302.

Galvin, K. M., \& Cooper, P.J. (1981). Research in communication education: Directional needs. Central States Speech Journal, 32 , 219-223.

Giroux, H. A. (1988). Teachers as intellectuals. Massachussetts: Bergin \& Garvey.

Good, T. L., \& Marshall, S. (1984). The Secial context of instruction. Orlando: Academic Press.

Johnson D. W. \& Johnson R. T. (1988). Cooperation in the classroom. Minnesota: Interaction Book Company.

Johnson, D. W., Maruyama, G., Johnson, R. T., Nelson, D., \& Skon, L. (1981). Effect of cooperative, competetive and individualistic goal structures on achievement: A meta-analysis. Esychological Bulletin, 89, 47-62.

Johnson, D.W., \& Johnson, R.T. (1990). Social skills for successful group work. Educational Leadership, 47, 31-33.

Kagan, S. (1986). Beyend language: Social and cultural factors in schooling lanquage minority students. Los Angeles: Evaluation, Dissemination and Assessment Center.

Kohn, A. (1986). No contest.: The case against competition. Boston: Houghton Mifflin.

Kohn, A. (1987). It's hard to get left out of a pair. Esycholegy Today, 21, 5357.

Lukes, S. (1974). Power: A radical view. London: Macmillan.

Matthews, R. (1986). Learning communities in the community college. The Community. Technical and Junior college Journal, 57, 44-47.

McCroskey, J. C., \& Richmond, V. P. (1983). Power in the classroom I: Teacher and student perceptions. Communication Education, 32, 175-184. 
Mouton, J. S., \& Blake, R. R. (1984). Synergegy. San Francisco: Jossey-Bass.

Noddings, N. (1984). Caring. Berkeley: University of California Press.

Noddings, N. (1988). An ethic of caring and its implications for instructional arrangements. American Journal of Education, 96, 215-229.

Nyquist, J. L., \& Booth, J. L. (1977). Instructional communication: A basic course for teachers. Communication Education, 26, 13-26.

O'Neill, W. (1969). Selected educational heresies. Glenview, IL: Scott Foresman.

Ozmon, H. (1970). Contemporary critics of education. Danville, IL: Interstate Printers.

Palmer, P. J. (1983). Io know as we are known. San Francisco: Harper and Row.

Palmer, P.J. (1987). Community, conflict, and ways of knowing: Ways to deepen our educational agenda. Change: The Magazine of Higher Learning, $19,20-25$.

Palmer, P.J. (1990). Good teaching: A matter of living the mystery. Change: The Magazine of Higher Learning, 22, 11-16.

Parks, S. (1986). The critical years. San Francisco: Harper and Row.

Salmon, P., \& Claire, H. (1984). Classroom collaboration. London: Routledge \& Kegan Paul.

Sapon-Shevin, M., \& Schniedewind, N. (1990). Selling cooperative learning without selling it short. Educational Leadership, 47, 63-65.

Shor, I. (1987). Critical teaching and evenday life. Chicago: University of Chicago Press.

Shor, I., \& Freire, P. (1987). A pedagogy for liberation: Dialogues for transforming education. South Hadley, MA: Bergin and Garvey.

Shulman, L. S. (1986). Paradigms and research programs in the study of teaching: A contemporary perspective. In M.C. Wittrock (Ed.), Handbook of Research on Teaching (pp. 3-36). New York: Macmillan.

Slavin, R. E. (1983). When does cooperative learning increase student achievement? Psychological Bulletin, 94, 429-445. 
Slavin, R. E. (1990). Research on cooperative learning: Consensus and controversy. Educational Leadership, 47, 52-54.

Soltis, J. F. (1984). On the nature of educational research. Educational Researcher, 32, 5-10.

Soltis, J. F. (1981). Philosophy of education since mid-century. New York: Teachers College Press.

Strain, J. P. (1971). Modern philosophies of education. New York: Random House.

Sprague, J. (1990). Assumptions about Individualism and Community that Underlie the Communication Curriculum. Presented at the Annual Conference of the Northwest Communication Association, Coeur D'Alene, Idaho.

Sprague, J. (1990). The goals of communication education. In J. A. Daly, G. W. Friedrich, \& A. L. Vangelisti (Eds), Teaching communication: Theory, research and methods (pp. 19-38). New Jersey: Lawrence Erlbaum Associates.

Sprague, J. (1992). Expanding the research agenda for instructional commun:cation: Raising some unasked questions. Communication Education, 41, 1-25.

Staton, A. Q. (1988). The interface of communication and instruction: Conceptual considerations and programmatic manifestations. communication Education 38, 364-391.

Staton-Spicer, A. Q., \& Wulff, D. H. (1984). Research in communication and instruction: Categorization and synthesis. Communication Education, $\underline{33}$, 377-391.

Tharp, R.G., \& Gallimore, R. (1988). Bousing minds to life. Cambridge University Press: New York.

Trenholm, S. (1986). Human Communication Theory. New Jersey: Prentice Hall.

Van Manen, S. (1990). Researching lived experience: Human science for an action sensitive pedagegy. Ontario: State University of New York Press. 